\title{
Coupled Transport of Solute and Water across Rabbit Gallbladder Epithelium*
}

\author{
Robert T. Whitlock $†$ and Henry O. Wheeler \\ (From the Department of Medicine, Columbia University College of Physicians \& Surgeons, \\ New York, N.Y.)
}

Recent studies of the isolated fish gallbladder by Diamond (2-4) showed that active, electrically neutral transport of sodium chloride provides the driving force for the absorption of water from the gallbladder lumen. The extent to which water absorption is coupled to active solute transport was indicated by the demonstration of net water absorption against significant osmotic gradients across the gallbladder wall. Similar findings were reported in studies of the isolated rabbit gallbladder (5) in which it was also demonstrated that bicarbonate participates in active solute transport. Transport of water against osmotic gradients was demonstrated in the canine gallbladder in vivo by Grim (6), who suggested that the findings were due to pinocytosis. "Uphill" water transport was also demonstrated in isolated intestinal segments by Parsons and Wingate (7).

In an effort to find a physical explanation for the remarkable coupling between solute and water movement observed in certain tissues, Curran (8) proposed and with McIntosh and Ogilvie successfully tested $(9,10)$ a model consisting of two membranes arranged in series, which could account for apparent "uphill" transport of water. Patlak, Goldstein, and Hoffman (11) recently published a detailed mathematical treatment of the Curran model from which they were able to predict a number of unexpected characteristics of such a system.

\footnotetext{
* Submitted for publication May 4, 1964; accepted July 27, 1964.

Presented in part at the meeting of the Federation of American Societies for Experimental Biology, April 1963 (1).

Supported by U. S. Public Health Service grant AM 07374

$\dagger$ Work begun while a fellow of the National Foundation and completed during tenure of a senior postdoctoral fellowship from the New York Heart Association.
}

The present studies have been undertaken to explore the phenomenon of solute-solvent coupling in the rabbit gallbladder under a variety of circumstances. With the equations of Patlak, Goldstein, and Hoffman at hand, it has been possible to compare the actual behavior of the gallbladder with the predicted behavior of a system analogous to the serial membrane model. Although alternative mechanisms could not be ruled out, the experimental observations appear to be consistent in every respect with the predicted characteristics of the Curran serial membrane model. The possible anatomical implications of these findings are discussed.

\section{Methods}

\section{In vivo experiments}

Male New Zealand rabbits weighing 5 to 8 pounds were anesthetized with pentobarbital. The gallbladder was exposed by reflecting the liver onto the thorax. With a dissecting microscope the cystic duct was incised and cannulated with a polyethylene tube. The cannula was ligated in place without injuring the blood vessels.

The lumen was emptied of bile by aspirating with a syringe and then rinsed 5 times with the prepared perfusion fluid (see below). At zero time the gallbladder was filled with a measured volume. After an interval usually of 6 to 7 minutes the period was ended by aspirating the entire contents into a clean syringe. The lumen was then refilled with the same fluid for a second period or rinsed and filled with a fluid of different osmolality. Blood was taken for determination of plasma osmolality. At the end the blood supply to the gallbladder was verified by illuminating the tissue with ultraviolet light and observing it through the dissecting microscope while injecting fluorescein ${ }^{1}$ into a peripheral vein.

The perfusion fluid was a modified Krebs-Henseleit solution (12) whose composition was as follows: $\mathrm{Na}^{+}$, $161 \mathrm{mEq}$ per $\mathrm{L} ; \mathrm{K}^{+}, 5.9 ; \mathrm{Ca}^{++}, 5.2 ; \mathrm{Mg}^{++}, 2.4 ; \mathrm{Cl}^{-}, 146$; $\mathrm{HCO}_{3}^{-}, 25$; $\mathrm{SO}_{4}^{--}, 2.4 ; \mathrm{H}_{2} \mathrm{PO}_{4}^{-}, 1.2$; glucose, $5.6 \mathrm{mM}$; and streptomycin, $50 \mathrm{mg}$ per $\mathrm{L}$. The total osmolality was

\footnotetext{
${ }^{1}$ Fluorescite, Moore Kirk Laboratories, Inc., Worcester, Mass.
} 
approximately the same as that of rabbit plasma (305 mOsm per $\mathrm{kg}$ ). To $60 \mathrm{ml}$ of this solution were added $2 \mu \mathrm{c} \mathrm{I} \mathrm{I}^{131}$-labeled albumin ${ }^{2}$ and $0.2 \mathrm{ml}$ "carrier" albumin. ${ }^{3}$ To portions of this fluid sucrose or $\mathrm{NaCl}$ was added to raise the osmolality above that of rabbit plasma by approximately 40, 80,120, and $160 \mathrm{mOsm}$ per $\mathrm{kg}$.

From each sample $200 \mu 1$ was taken for assay of radioactivity in a well scintillation counter ${ }^{4}$ and for determination of osmolality with the small sample operating head of a model G62 Fisk osmometer. ${ }^{5}$ In two studies $100-\mu 1$ samples were taken for determinations of $\mathrm{Na}^{+}$.

\section{In vitro experiments}

Experiments were carried out in vitro at a constant room temperature of $37^{\circ} \mathrm{C}$. The procedures and apparatus for removing and studying the rabbit gallbladder in vitro were described in detail previously (5). The apparatus provides circulating mucosal and serosal baths (volumes approximately 4.5 and $19 \mathrm{ml}$, respectively), which can be sampled or completely exchanged without injuring the gallbladder. The net water flux is determined by serial measurements of the volume of the serosal bath.

Gallbladders were rinsed and suspended in bathing fluids whose composition was identical with the KrebsHenseleit solution used in the in vivo studies with the exception that the concentrations of $\mathrm{Na}^{+}, \mathrm{Cl}^{-}$, and sucrose were adjusted as indicated in Table II. The serosal bath volume was measured at intervals of 10 to 20 minutes. When the water flux appeared steady, the mucosal fluid was sampled. After an interval of at least 40 minutes, a second mucosal sample was obtained. Mucosa and serosa were then rinsed with the fluids to be used for a second experiment, which was conducted similarly to the first. A given gallbladder preparation was usually used for two different experiments. At the end the volume of the mucosal bath was determined from the volume of distribution of sulfobromophthalein (BSP) added to the mucosal fluid.

\section{Measurements of electrical potential differences}

The electrical potential difference (PD) of the mucosal bath with respect to the serosal bath was measured at intervals during all in vitro studies. Identical mucosal and serosal salt bridges were made fresh for each study by aspirating Krebs solution containing 4\% agar into polyethylene tubes. Each bath was connected by such a bridge to a solution of saturated $\mathrm{KCl}$ that was in contact with a standard calomel electrode. The electrodes

\footnotetext{
2 RISA, I ${ }^{131}$-radioiodinated serum albumin (human), Abbott Laboratories, North Chicago, Ill.

${ }^{3}$ Normal serum albumin (human), salt-poor, U.S.P., approximately $25 \%$ in buffer, Cutter Laboratories, Berkeley, Calif.

4 Packard Instrument Co., model 422 scintillation crystal and model 255 scaler, La Grange, Ill.

5 Fisk Associates, Bethel, Conn.
}

were connected to a high impedance millivoltmeter. ${ }^{6}$ In the experiments of groups $F$ and $G$ (Table II) the recorded $P D$ was corrected for an estimated junction potential of $1.5 \mathrm{mv}$ between the salt bridges and the mucosal and serosal bathing fluids, respectively.

\section{Analytical methods}

Samples were diluted in duplicate, and the $\mathrm{Na}^{+}$concentration was measured in an internal standard flame spectrophotometer. ${ }^{7}$ Sucrose was measured by the resorcinol method of Schreiner (13).

\section{Calculations}

In vivo experiments. Net water flux $(\Delta \mathrm{w})$ was calculated from the change in concentration of $\mathrm{I}^{131}$-albumin and net $\mathrm{Na}^{+}$flux $\left(\Delta \mathrm{Na}^{+}\right)$from the change in $\mathrm{Na}^{+}$concentration in mucosal fluid. The arithmetic mean of the mucosal fluid osmolalities measured at the beginning and end of each period was used to estimate the average osmotic gradient between lumen and plasma.

In vitro experiments. Net water flux and net $\mathrm{Na}^{+}$flux were calculated from the changes in volume of the serosal fluid and from the $\mathrm{Na}^{+}$concentrations measured in mucosal fluid and replacement solutions as described previously (5).

The osmolality $\left(\Pi_{A}\right)$ of the hypothetical absorbed solution was estimated from the formula:

$$
\Pi_{\mathrm{A}}=\frac{\Delta \mathrm{Na}^{+}}{\Delta \mathrm{w}} \times 1,000 \times 2 \times 0.9,
$$

where 0.9 is the approximate osmotic coefficient of $\mathrm{NaCl}$ in aqueous solutions of this composition.

\section{Results}

In vivo experiments. The results of studies on intact gallbladders in vivo are summarized in Table I. In the first study $(\mathrm{N})$ the perfusion fluid contained $40 \mathrm{mM}$ sucrose and was hypertonic with respect to plasma by $48 \mathrm{mOsm}$ per $\mathrm{kg}$. The gallbladder was repeatedly refilled with perfusion fluid immediately after each emptying, and seven consecutive periods were obtained, lasting from 5.5 to 8 minutes each, during which the mucosal contents were hypertonic with respect to plasma at all times. Thus, an osmotic gradient averaging approximately $34 \mathrm{mOsm}$ per $\mathrm{kg}$ was maintained for 45 minutes, and despite this the gallbladder absorbed water at the average rate of 796 $\mu \mathrm{l}$ per hour (range, 634 to $982 \mu \mathrm{l}$ per hour). The second study $(\mathrm{O})$ showed similar results. These results demonstrated that the gallbladder in vivo,

\footnotetext{
${ }^{6}$ Model 600 A electrometer, Keithley Instruments, Inc., Cleveland, Ohio.

` Baird Associates, Inc., model DB-4, Cambridge, Mass.
} 
TABLE I

Absorption of water from hypertonic mucosal fluid by the rabbit gallbladder in vivo

\begin{tabular}{|c|c|c|c|c|c|c|}
\hline & $\begin{array}{c}\text { Plasma } \\
\text { osmolality }\end{array}$ & $\begin{array}{l}\text { Perfusion } \\
\text { fluid } \\
\text { osmolality }\end{array}$ & $\begin{array}{l}\text { Average } \\
\text { osmotic } \\
\text { gradient }\end{array}$ & $\begin{array}{c}\text { Consecu- } \\
\text { tive } \\
\text { periods }\end{array}$ & $\underset{(\text { mean })}{\Delta w^{*}}$ & $\underset{(\text { mean })}{\Delta \mathrm{Na}^{+}}$ \\
\hline & $\mathrm{mOsm} / \mathrm{kg}$ & $\mathrm{mOsm} / \mathrm{kg}$ & $\mathrm{mOsm} / \mathrm{kg}$ & no. & $\mu l / h r$ & $\mu E q / h r$ \\
\hline \multicolumn{7}{|c|}{$\begin{array}{l}\text { 1. Mucosal fluid made hypertonic with sucrose } \\
\mathrm{N}\end{array}$} \\
\hline $11 / 8 / 63$ & 303 & 351 & 34 & 7 & 796 & \\
\hline$\stackrel{\mathrm{O}}{\mathrm{O}}$ & 295 & 347 & 35 & 7 & 692 & \\
\hline$\stackrel{P}{P}$ & 311 & $\begin{array}{l}350 \\
386 \\
426 \\
463\end{array}$ & $\begin{array}{r}18 \\
51 \\
73 \\
100\end{array}$ & $\begin{array}{l}2 \\
2 \\
3 \\
1\end{array}$ & $\begin{array}{r}744 \\
634 \\
248 \\
-\quad 38\end{array}$ & $\begin{array}{l}236 \\
244 \\
238 \\
167\end{array}$ \\
\hline$\stackrel{Q}{Q}$ & 303 & $\begin{array}{l}350 \\
386 \\
427\end{array}$ & $\begin{array}{l}29 \\
57 \\
83\end{array}$ & $\begin{array}{l}3 \\
3 \\
3\end{array}$ & $\begin{array}{r}556 \\
123 \\
-270\end{array}$ & $\begin{array}{l}235 \\
238 \\
223\end{array}$ \\
\hline$\underset{11 / 22 / 63}{\mathrm{~S}}$ & 292 & $\begin{array}{l}343 \\
383 \\
423 \\
306\end{array}$ & $\begin{array}{r}39 \\
70 \\
99 \\
8\end{array}$ & $\begin{array}{l}2 \\
2 \\
2 \\
3\end{array}$ & $\begin{array}{r}-30 \\
-258 \\
-516 \\
312\end{array}$ & \\
\hline \multicolumn{7}{|c|}{ 2. Mucosal fluid made hypertonic with $\mathrm{NaCl}$} \\
\hline $12 / 3 / 63$ & 302 & $\begin{array}{l}310 \\
347 \\
388 \\
421\end{array}$ & $\begin{array}{r}4 \\
32 \\
64 \\
91\end{array}$ & $\begin{array}{l}2 \\
2 \\
2 \\
2\end{array}$ & $\begin{array}{r}434 \\
280 \\
-170 \\
-715\end{array}$ & \\
\hline $12 / \mathrm{U} / 63$ & 336 & $\begin{array}{l}310 \\
354 \\
386 \\
400 \\
453\end{array}$ & $\begin{array}{r}-28 \\
14 \\
43 \\
60 \\
113\end{array}$ & $\begin{array}{l}2 \\
2 \\
2 \\
2 \\
2\end{array}$ & $\begin{array}{r}505 \\
434 \\
249 \\
120 \\
-\quad 65\end{array}$ & \\
\hline
\end{tabular}

${ }^{*} \Delta w=$ net water flux; $\Delta \mathrm{Na}^{+}=$net $\mathrm{Na}^{+}$flux.

like the isolated gallbladder $(4,5)$, was able to absorb water at a brisk rate and against an opposing osmotic gradient.

In the remaining five studies the osmotic gradient was systematically varied within each study. Gradients of approximately 40, 80,120, and 160 $\mathrm{mOsm}$ per $\mathrm{kg}$ were produced by adding sucrose in three studies ( $\mathrm{P}, \mathrm{Q}$, and $\mathrm{S}$ ) and $\mathrm{NaCl}$ in two studies ( $\mathrm{T}$ and $\mathrm{U}$ ). A typical study $(\mathrm{P})$ is shown in Figure 1. The average osmotic gradient for each period is represented by a box in the lower graph. In the middle graph the volume of water absorbed is plotted against time so that the slope is proportional to the net water flux. In the upper graph the net water flux is plotted against the average osmotic gradient, and the straight lines connect the mean of each group. With increasing osmotic gradients there were a diminution and ulti- mately a reversal in net water flux. That the diminution of water flux was not merely a function of elapsed time is shown by the results with study $\mathrm{S}$, where the usual sequence was reversed in the final periods. In this study the water flux, which had been negative at high osmotic gradients, reversed and became appropriately positive at a low gradient.

Net $\mathrm{Na}^{+}$fluxes from two studies are shown in the right hand column of Table I. The over-all average net $\mathrm{Na}^{+}$flux for study $\mathrm{P}$ was $226 \mu \mathrm{Eq}$ per hour, and for study $Q$ it was $232 \mu \mathrm{Eq}$ per hour. The results at varying osmotic gradients demonstrate that, unlike the water flux, the $\mathrm{Na}^{+}$ flux is relatively unaffected by the opposing osmotic pressures. Some diminution of net $\mathrm{Na}^{+}$flux is undoubtedly caused by back diffusion of $\mathrm{Na}^{+}$at the higher sucrose concentrations. This is be- 
cause the absorption of hypertonic fluid under these conditions leads to a marked decrease in mucosal $\mathrm{Na}^{+}$concentration. For example, the mucosal $\mathrm{Na}^{+}$concentration was only $98 \mathrm{mEq}$ per $\mathrm{L}$ at the end of the last period of study $(\mathrm{P})$.

Figure 2 is a graph constructed from the last five studies of Table I, which are the studies where the adverse osmotic gradient was systematically varied. For each study the data at each osmotic level were averaged to yield a single point. The zero intercepts demonstrate approximately the osmotic gradients necessary to reverse the direction of net water flow. The range was from 38 to $98 \mathrm{mOsm}$ per $\mathrm{kg}$. There was no apparent difference whether the fluid was made hypertonic by adding sucrose or by adding $\mathrm{NaCl}$.

Studies in vitro of solvent-solute coupling. The results of in vitro studies of solvent-solute coup-
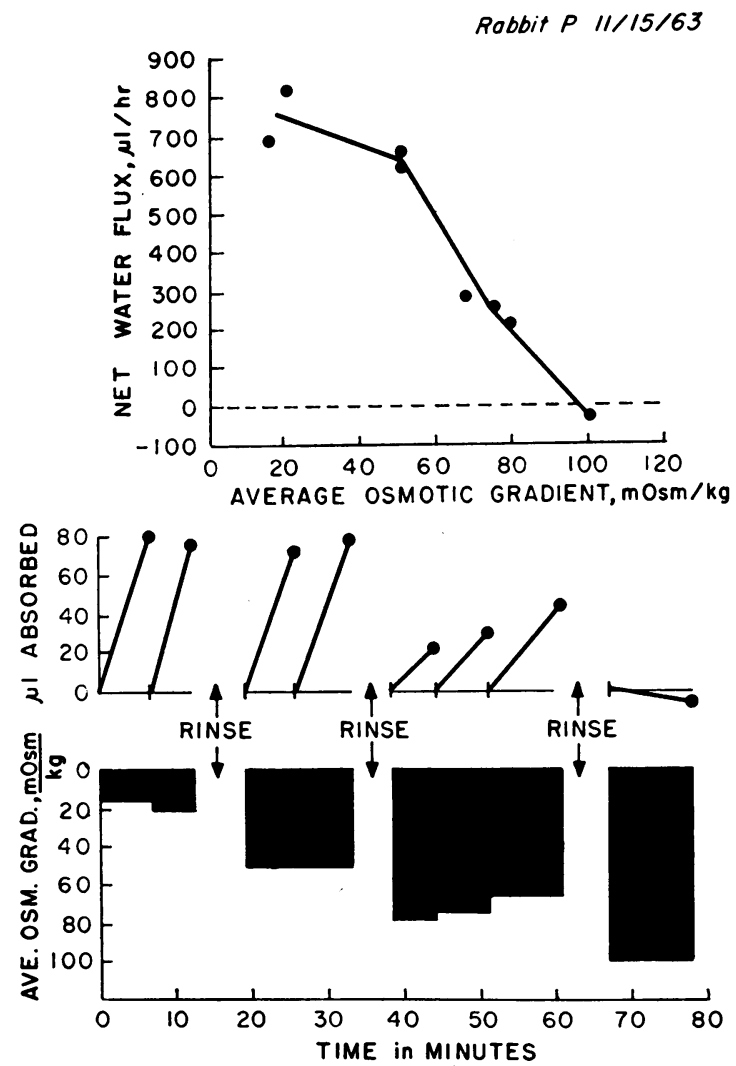

Fig. 1. WATER tRANSPORT AGainst various osmotic Gradients in vivo. Mucosal fluid was made progressively hypertonic to this rabbit's plasma with sucrose$40,80,120$, and $160 \mathrm{mM}$, respectively. The information in the middle and lower graphs was replotted in the uppermost graph with lines connecting the means.

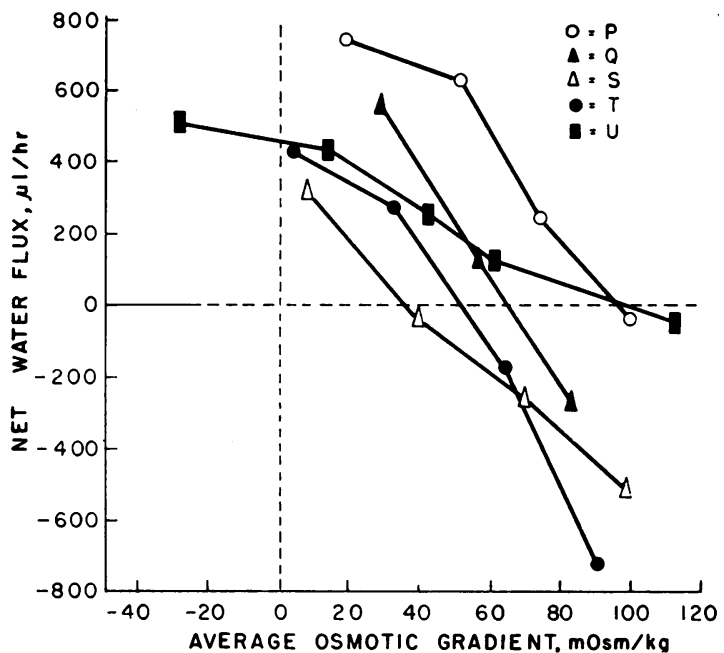

Fig. 2. Water tRANSPORT Against various osmotic GRADIENTS IN vivo. Data were taken from the last five studies in Table I. For each study, results at each degree of osmolality were averaged to yield a single point. Points from the same animal were connected by a line whose zero intercept indicated approximately the osmotic gradient necessary in each preparation to reverse water absorption. Points in the upper right quadrant signify "uphill" water transport.

ling are shown in Table II. Although the osmolality of the bathing fluids was varied from one experimental group to another, in a given experiment the mucosal fluid was always isosmotic with respect to the serosal fluid.

Effects of changing osmolality. The experiments in category 1 of Table II are plotted individually in Figure 3 to show the effect on coupled water transport of raising and lowering the bath osmolality by changing the concentrations of $\mathrm{Na}^{+}$ and $\mathrm{Cl}^{-}$ions. The closed circles in Figure 3 (and Figures 4,5 , and 6 ) represent the 10 experiments of group B with plain, isotonic bathing fluids (284 mOsm per $\mathrm{kg}$ ). These were considered to be control experiments, and the results were replotted on each of several graphs to provide a visual comparison. The inverted open triangles in Figure 3 represent the experiments of group $\mathrm{A}$ in hypotonic media with an osmolality of $200 \mathrm{mOsm}$ per $\mathrm{kg}$. The amount of water that was transported per mole of transported $\mathrm{Na}^{+}$was clearly increased in hypotonic media. The ratio, $\Delta \mathrm{Na}^{+} / \Delta \mathrm{w}$, which has the familiar dimensions of solute concentration, may be thought of as the concentration of $\mathrm{Na}^{+}$in a hypothetical absorbed solution. This value was 


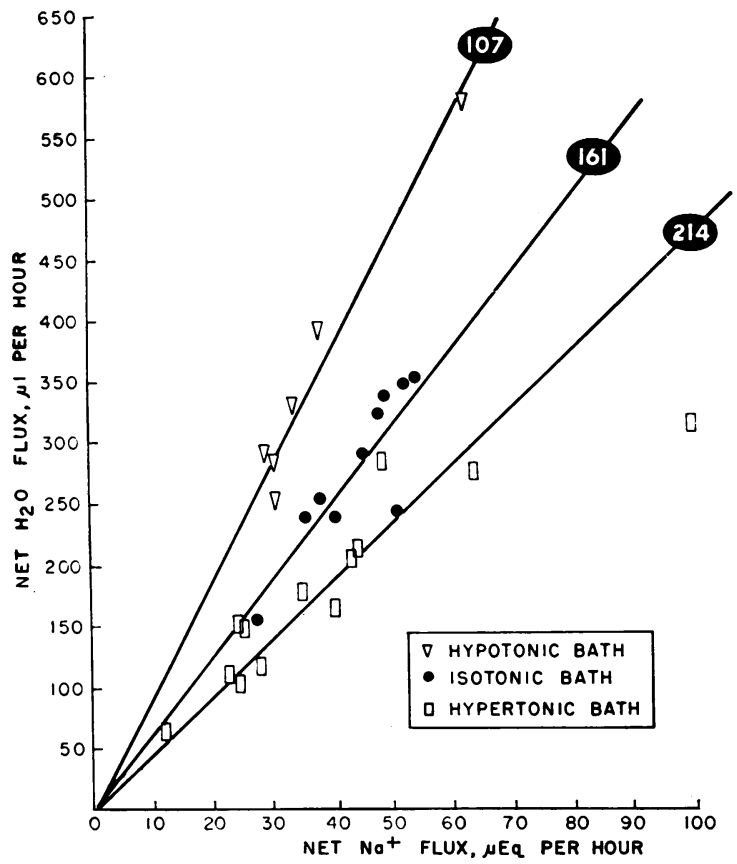

Fig. 3. EFFECT OF BATH OSMOLALity ON COUPLED WATER TRANSPORT. Each mean $\Delta \mathrm{Na}^{+} / \Delta \mathrm{w}$ (net $\mathrm{Na}^{+}$flux/net water flux) is represented by a line and number within an ellipse. Water transport was increased in hypotonic media and decreased in hypertonic media.

calculated for each experiment, and the mean $\Delta \mathrm{Na}^{+} / \Delta \mathrm{w}$ for each group of experiments was represented by a line and by the value within the ellipse. The difference between the mean values of $\Delta \mathrm{Na}^{+} / \Delta \mathrm{w}$ in hypotonic and in isotonic media, 107 and $161 \mathrm{mEq}$ per $\mathrm{L}$, is statistically highly significant $(p<0.001)$. In contrast, the open squares represent experiments of group $\mathrm{C}$ in hypertonic media with an osmolality of 397 mOsm per $\mathrm{kg}$; coupled water transport was clearly decreased. The difference between the mean values of $\Delta \mathrm{Na}^{+} / \Delta \mathrm{w}$ in hypertonic and in isotonic media, 214 and $161 \mathrm{mEq}$ per $\mathrm{L}$, is highly significant $(\mathrm{p}<$ $0.005)$.

Effect of sucrose in both baths. The experiments in category 2 of Table II showed the effect on coupled water transport of the presence of a large, impermeant solute, sucrose, in both mucosal and serosal baths. In group $\mathrm{D}$, for example, the bath osmolality was $284 \mathrm{mOsm}$ per $\mathrm{kg}$, the sucrose concentration was $85 \mathrm{mM}$, and the $\mathrm{Na}^{+}$ concentration was $97 \mathrm{mEq}$ per L. In effect, the hypotonic media of group A was made isotonic by adding sucrose. In these experiments, sucrose

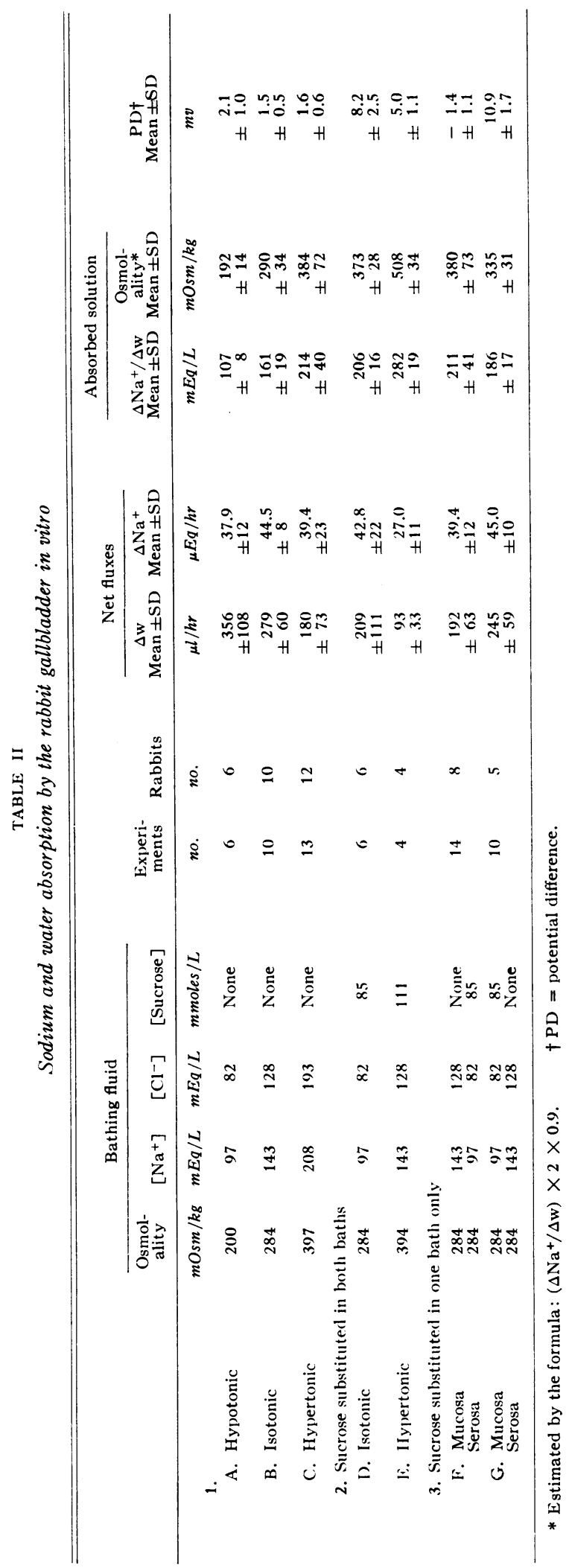




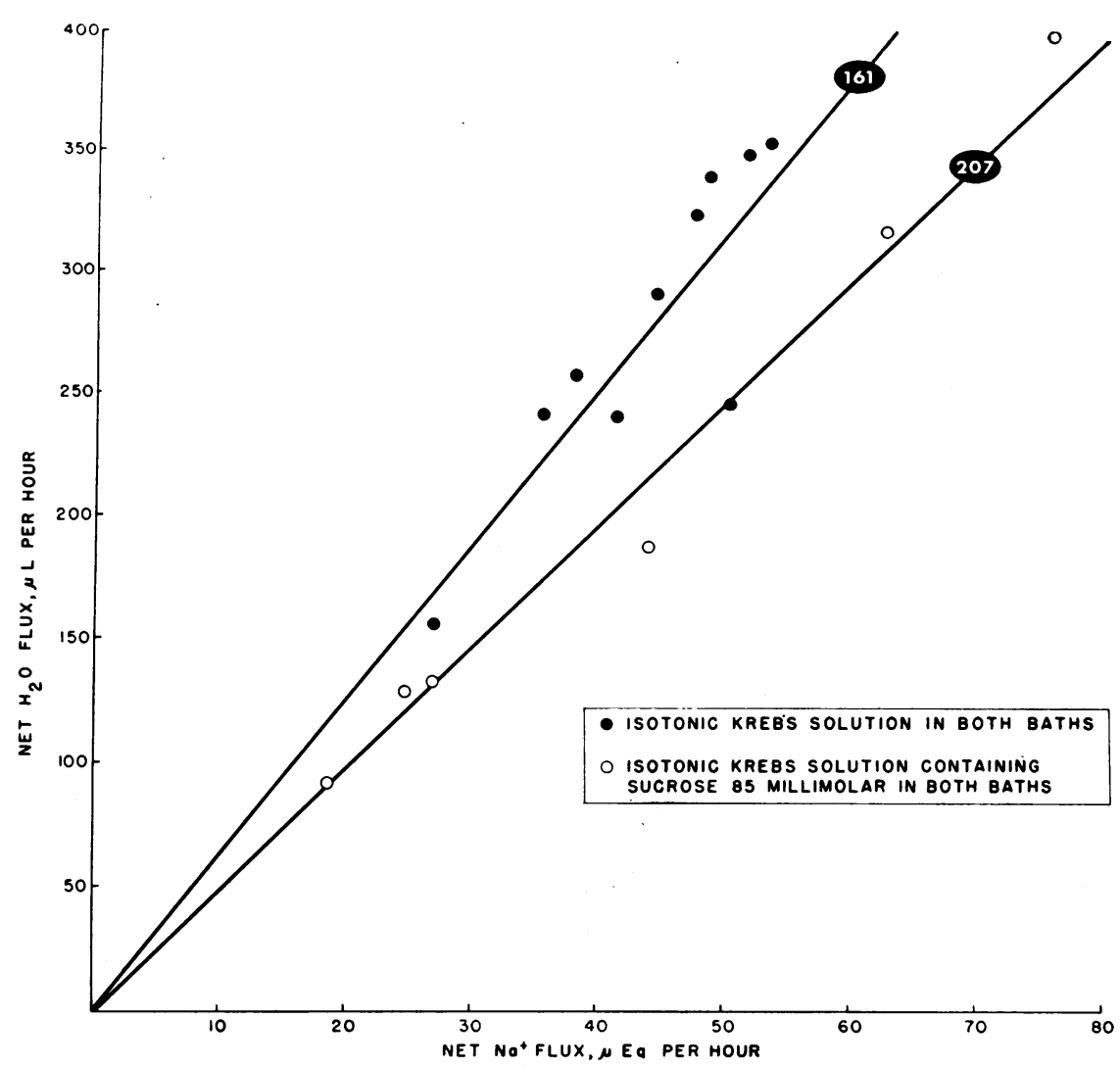

Fig. 4. EFFECT OF SUCRose ON COUPLED WATER TRANSPORT. Water transport was decreased in the presence of sucrose.

being impermeant, $\mathrm{Na}^{+}$and $\mathrm{Cl}^{-}$ions were still the major transported solute species, but they were not the only major osmotic constituents of the bathing fluids. Figure 4 compares the experiments of group D with those of group B. Although the total osmolality of the media was identical in the two groups, coupled water transport was clearly decreased in the presence of sucrose. The difference between the mean values of $\Delta \mathrm{Na}^{+} / \Delta \mathrm{w}$ in sucrose media vs. plain media, 206 vs. $161 \mathrm{mEq}$ per $\mathrm{L}$, is highly significant $(\mathrm{p}<$ 0.001 ). Comparison of the experiments of group $\mathrm{E}$ with those of group $\mathrm{C}$ also demonstrated decreased coupled water transport in the presence of sucrose.

Effect of sucrose in one bath. The effect of sucrose substitution in each bath alone was tested in the experiments of category 3. Plain, isotonic fluid was put in one bath, and an isotonic fluid containing $85 \mathrm{mM}$ sucrose was put in the other. In Figure 5 the open circles show the experiments of group $\mathrm{F}$ with sucrose in the serosal fluid only. The difference between the mean values of $\Delta \mathrm{Na}^{+} / \Delta \mathrm{w}$ in serosal sucrose experiments vs. plain isotonic experiments, 211 vs. $161 \mathrm{mEq}$ per $\mathrm{L}$, is highly significant $(p<0.005)$. Coupled water transport was decreased by serosal sucrose. The effect was quite similar to that of sucrose in both baths.

In Figure 6 the open circles show the experiments of group $G$ with sucrose in the mucosal bath only. The difference between the mean values of $\Delta \mathrm{Na}^{+} / \Delta \mathrm{w}$ in the mucosal sucrose experiments vs. the plain isotonic experiments, 186 vs. $161 \mathrm{mEq}$ per L, is statistically probably significant $(\mathrm{p}<0.02)$.

In Figure 7 the transport of salt and water was characterized as absorption of a hypothetical solution of $\mathrm{NaCl}$, whose osmolality was estimated (see Calculations) for comparison with that of the bathing media. Experiments of groups A, B, and $C$ showed that the osmolality of the absorbed 
solution was approximately the same as the osmolality of the bath when the bathing media was composed of plain Krebs solution. The presence of sucrose, in both baths, or in either bath alone was associated with absorption of a fluid that was hypertonic with respect to the bathing media.

Electrical potential difference. Measurements of the PD made during in vitro studies are shown in Figure 8. There was essentially no difference between values of the $P D$ in experiments of groups $\mathrm{A}, \mathrm{B}$, and $\mathrm{C}$. The mean of all values was $1.7 \pm \mathrm{SD} 0.7 \mathrm{mv}$ (mucosa positive). The presence of sucrose in both baths, groups $\mathrm{D}$ and $\mathrm{E}$, was associated with a rise in $\mathrm{PD}$ to $8.2 \pm \mathrm{SD}$ $2.5 \mathrm{mv}$ and to $5.0 \pm \mathrm{SD} 1.1 \mathrm{mv}$, respectively. In group F serosal sucrose substitution was associated with a slight negative shift in $\mathrm{PD}$ to a mean of $-1.4 \pm \mathrm{SD} 1.1 \mathrm{mv}$. In group $\mathrm{G}$ mucosal sucrose substitution was associated with a large positive shift in $\mathrm{PD}$ to a mean of $10.9 \pm \mathrm{SD} 1.7$ mv.

Permeation of sucrose. In six experiments, three of group $\mathrm{G}$ and three of group $\mathrm{F}$, the movement of sucrose across the gallbladder wall was measured. Average net flux was $1.6 \mu$ moles per hour (range, 0.7 to $4.9 \mu$ moles per hour). Since the net $\mathrm{Na}^{+}$ flux in these groups was approximately $40 \mu \mathrm{Eq}$ per hour (representing $80 \mu$ Osm per hour), sucrose was considered to be essentially impermeant in these and all other experiments.

\section{Discussion}

The rabbit gallbladder in vitro absorbs water uphill and can do so against impressive osmotic gradients (5). The results of the studies shown in Table I demonstrate that the ability to absorb water uphill exists also for the gallbladder in vivo, when the blood supply is intact, against gradients of 38 to $98 \mathrm{mOsm}$ per $\mathrm{kg}$ (Figure 2). It seems unlikely that the gallbladder mucosa is called upon to work against gradients of this size under natural conditions. The experimental demonstration of uphill water transport against large osmotic gradients does, however, compel us to acknowledge the phenomenon of coupling of sol-

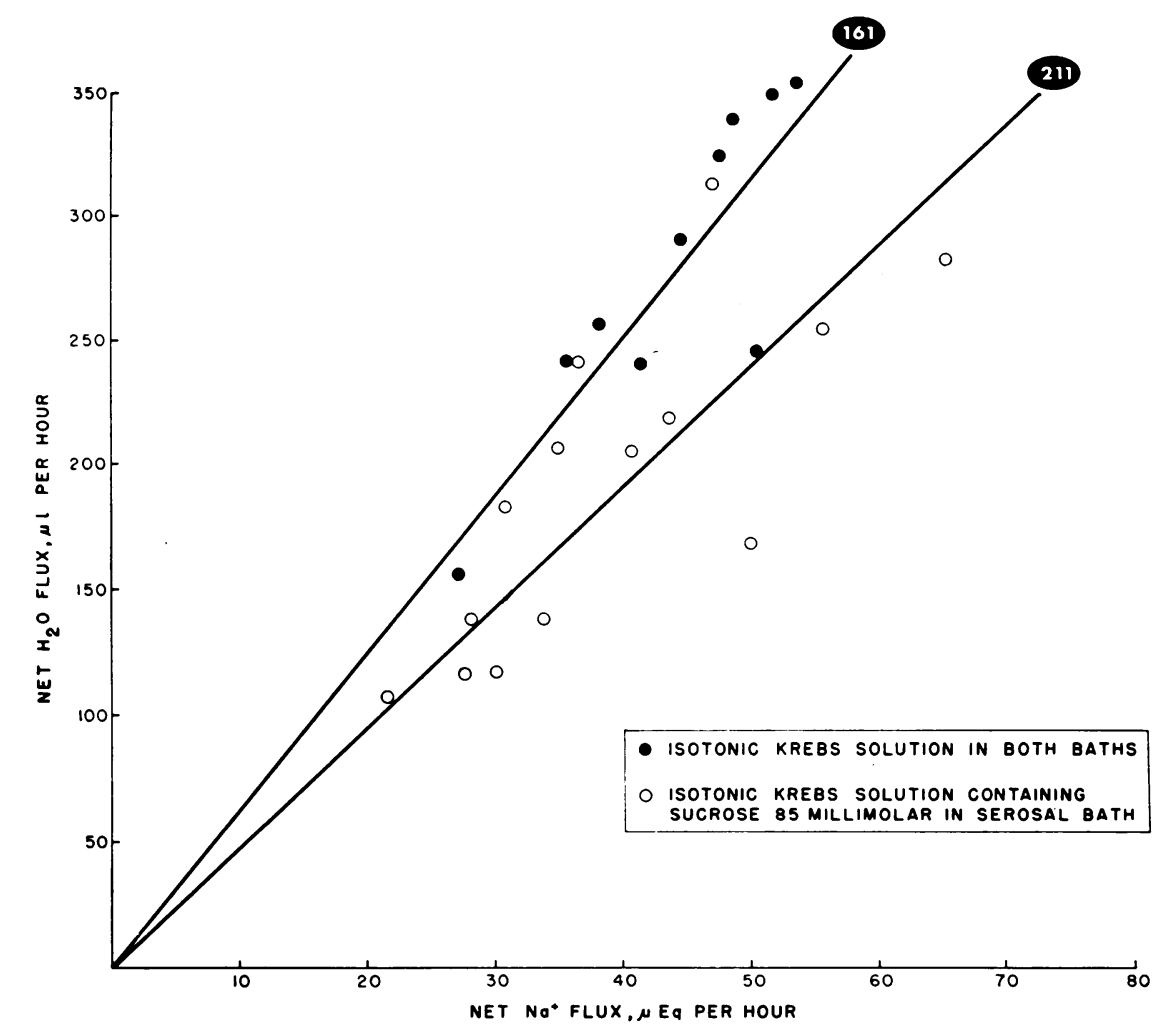

Fig. 5. EFfect of Serosal sucrose on COUPled Water transport. Water transport was decreased with sucrose in the serosal bath only. 


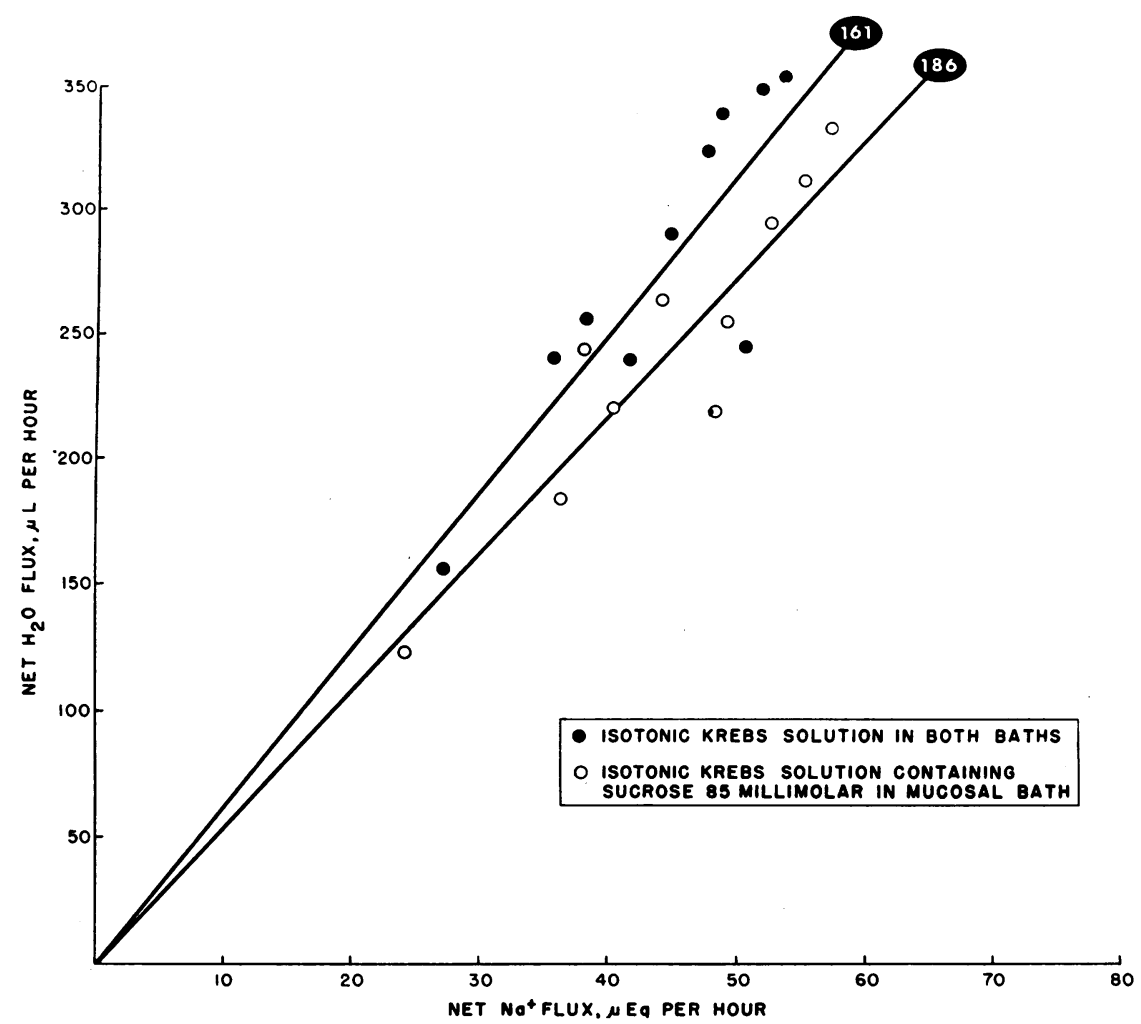

Fig. 6. EFFECT OF MUCOSAL SUCROSE ON COUPLED WATER TRANSPORT. Water transport was decreased by sucrose in the mucosal bath alone.

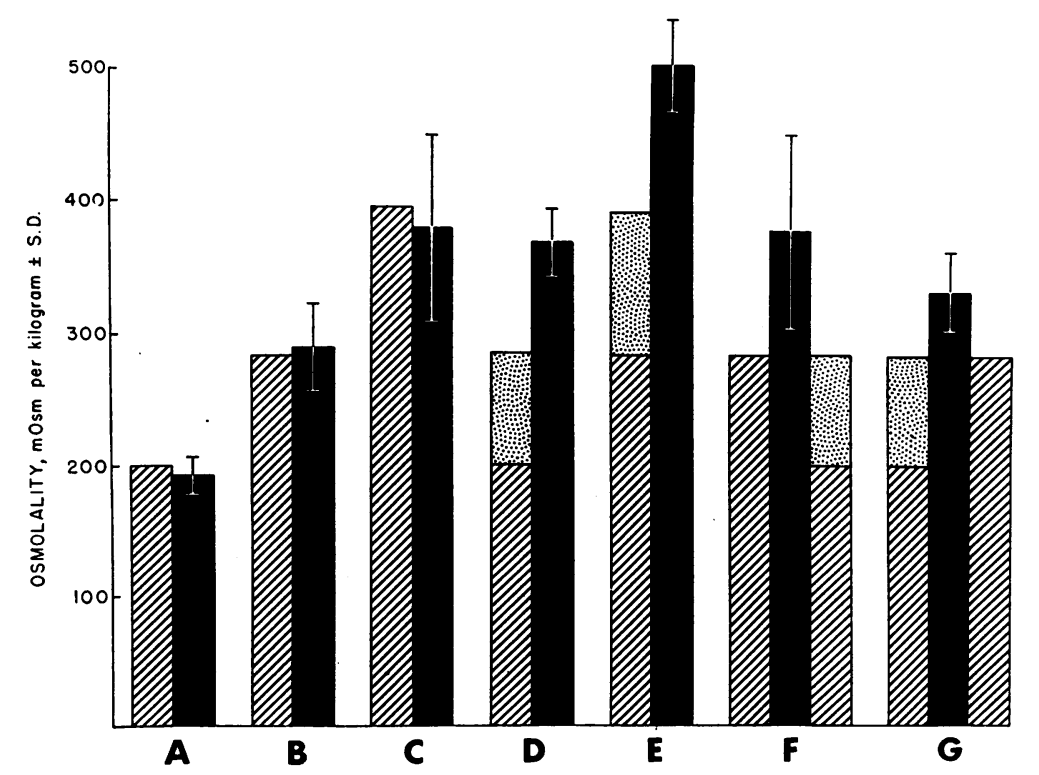

Fig. 7. EFFeCt of Bath osmolality and sucrose on the osmolality OF THE "ABSORBED SOLUTION." The letters on the abscissa correspond to the experimental groups of Table II. Length of bars is proportional to osmolality. Solid bars represent the "absorbed solutions." The hatched and stipled bars represent the bathing fluids, the stippling being proportional to sucrose. For $\mathrm{F}$ and $\mathrm{G}$ the left bar represents mucosal fluid and the right bar, serosal fluid. 


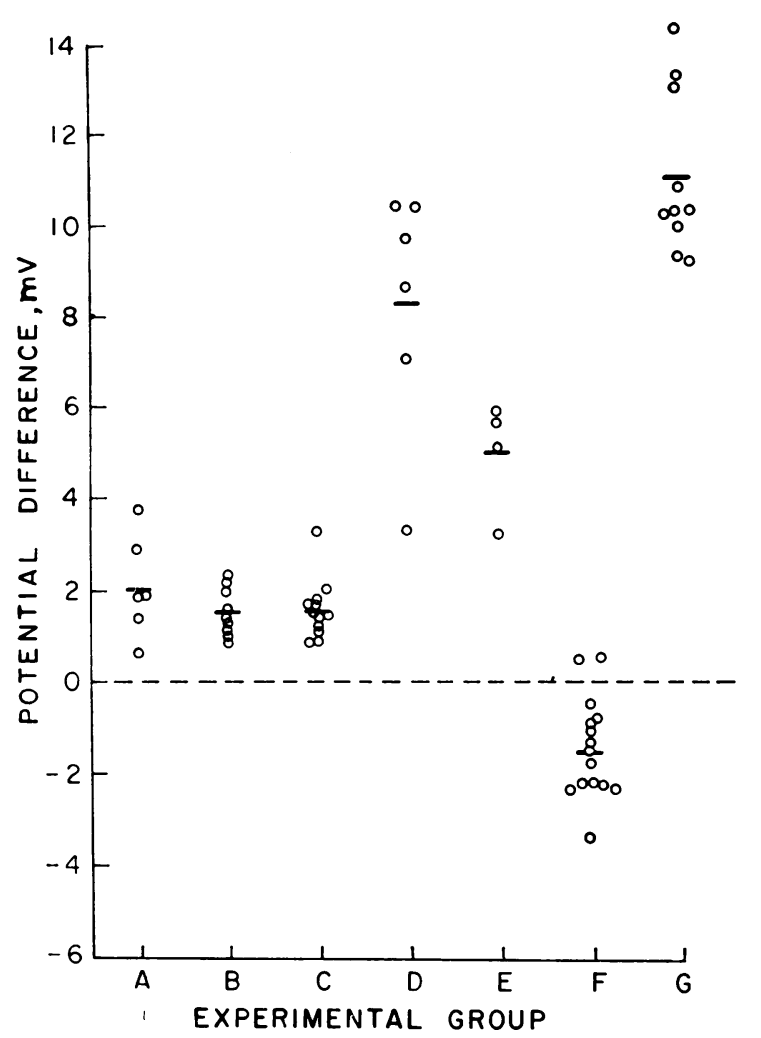

Fig. 8. Potential differences (PD) from in vitro studies. The sign of the PD is that of mucosa relative to serosa. Letters on the abscissa correspond to experimental groups in Table II. Horizontal bars represent mean values within each group.

vent transport to solute transport. The physiological importance of the coupling mechanism is probably not so much that it makes possible uphill transport, but rather that it makes possible very efficient water absorption under approximately isotonic conditions.

The in vitro studies tabulated in Table II, which were done in the absence of transmembrane osmotic gradients, revealed several previously undemonstrated characteristics of the coupling mechanism. When the osmolality of the bathing media was reduced, there was an increase in water transport relative to sodium transport, and when the osmolality of the bathing media was increased, there was a decrease in water transport relative to sodium transport. The changes in water flux were such that the absorbed solution was practically isosmotic with respect to the bath (Figure 7; A, B, and C) as long as the bathing media were composed chiefly of transportable solutes, i.e., $\mathrm{Na}^{+}$ and $\mathrm{Cl}^{-}$ions. Partial replacement of transportable solutes with an impermeant solute, sucrose, resulted in a decrease in water transport relative to sodium transport whether the replacement was done on both sides or, remarkably, in either bath alone (Figure 7; D, E, F, and G). A theory that can explain coupled water transport by the gallbladder should account for all of the above phenomena.

Serial membrane hypothesis of Curran. To account for uphill transport by the small intestine Curran (8) proposed the operation of a double barrier system such as that illustrated in Figure 9. Mucosal fluid is represented by 1 and serosal fluid by r. Curran suggested that barrier 1 would be semipermeable and that barrier 2 would be nonselective but functional as a mixing barrier. Compartment $\mathrm{m}$ would be sufficiently confined to permit development of a hydrostatic pressure. Curran and his associates $(9,10)$ demonstrated with a model apparatus that such a scheme could accomplish apparent uphill water transport.

In a living membrane, such a system might be envisioned oversimply to function as follows: Active transport of solute across barrier 1 would sustain a steady state in which $\mathrm{m}$ was slightly hyperosmotic with respect to 1 . In response to this osmotic gradient water would flow through barrier 1 . The resulting hydrostatic pressure in $\mathrm{m}$ would drive the solution from $\mathrm{m}$ into $\mathrm{r}$. The composition of the solution that traversed such a system would be a complex function of the filtration and reflection properties of the two barriers.

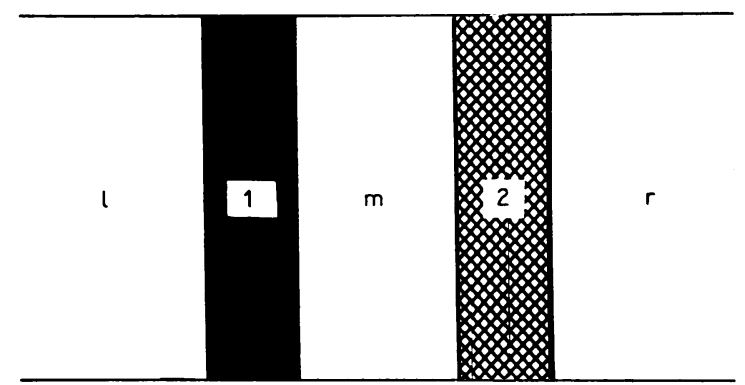

Fig. 9. Curran serial membrane model. The two barriers separate the system into three well-stirred compartments. The middle compartment $\mathrm{m}$ is confined to permit development of positive hydrostatic pressure. Active solute transport is assumed to occur across barrier 1 in the direction of 1 to $\mathrm{m}$. Application of the model to the present problem is discussed in the text. 
Patlak and associates (11) and Kedem and Katchalsky (14) recently derived equations to describe the movement of solute and solvent across a system consisting of two major barriers arranged in series. The equations of Patlak and associates include a consideration of active solute transport and are therefore applicable to the present discussion. In their system Patlak and associates have assumed active transport of solute across the first barrier (Figure 9) and have further assumed that there is no direct interaction between active solute transport and the passive fluxes of solute and solvent. Analysis of those equations that are applicable to the present experiments (see Appendix) leads to the conclusion that the observed behavior of the rabbit gallbladder is entirely consistent with theoretical predictions for a serial membrane model provided that the individual components of the model have the following characteristics: 1) The second barrier must be virtually nonselective with respect to transported solute and solvent (i.e., it must have a reflection coefficient close to zero). 2) The first barrier must be appreciably less permeable to transported solute than to solvent (i.e., its reflection coefficient must be greater than zero). 3) Both barriers must be readily conductive for solvent (i.e., they must have large hydraulic conductivities).

If the foregoing conditions are satisfied, the serial membrane model, like the gallbladder, will transport a solution virtually isotonic with respect to the external media when the media consist of identical solutions of permeant solute. Moreover, when an impermeant solute is partially substituted for permeant solute on either or both sides, the theoretical model will, like the gallbladder, transport a solution that is hypertonic with respect to the osmolality of the media.

By substitution of reasonable numerical values for the various physical constants in the appropriate equations (see Appendix), it is possible to predict the quantitative relationship between the concentration of solute in the transported solution $\left(\mathrm{J}_{\mathrm{s}} / \mathrm{J}_{\mathrm{v}}\right)$ and the concentrations of permeant solute $\left(c_{s}\right)$ and impermeant solute $\left(c_{i}\right)$ in the media. These predictions can be compared with actual values derived from experimental observations (Table II) as follows: category 1 (A, B, C), permeant solute only: predicted: $\mathrm{J}_{\mathrm{s}} / \mathrm{J}_{\mathrm{v}} \approx \mathrm{c}_{\mathrm{s}}$, ob- served: $\mathrm{J}_{\mathrm{s}} / \mathrm{J}_{\mathrm{v}}=\mathrm{c}_{\mathrm{s}}$; category $2(\mathrm{D}, \mathrm{E})$, impermeant solute on both sides: predicted: $\mathrm{J}_{\mathrm{s}} / \mathrm{J}_{\mathrm{v}} \approx \mathrm{c}_{\mathrm{s}}$ $+2.5 c_{i}$, observed: $J_{s} / J_{v}=c_{s}+2.0 c_{i}$; category $3 \mathrm{~F}$, impermeant solute on right (serosal) side: predicted: $\mathrm{J}_{\mathrm{s}} / \mathrm{J}_{\mathrm{v}} \approx \mathrm{c}_{\mathrm{rs}}+2.1 \mathrm{c}_{\mathrm{ri}}$, observed: $\mathrm{J}_{\mathrm{s}} / \mathrm{J}_{\mathrm{v}}=$ $c_{r s}+2.1 c_{r i}$; category $3 \mathrm{G}$, impermeant solute on left (mucosal) side: predicted: $\mathrm{J}_{\mathrm{s}} / \mathrm{J}_{\mathrm{v}} \approx \mathrm{c}_{\mathrm{ls}}+1.4$ $c_{1 i}$, observed: $J_{s} / J_{v}=c_{l s}+1.6 c_{1 i}$.

That the theoretical predictions agree fairly well with the experimental data does not validate the numerical values of the constants employed in their calculation. Other combinations of permeability and reflection coefficients might yield predictions almost as close to, and statistically indistinguishable from, the actual experimental results. In particular, the selection of the value 0.9 for the reflection coefficient of barrier 1 for $\mathrm{NaCl}$ is completely arbitrary. The examples do illustrate, however, that the experimental results are entirely consistent with the theoretical behavior of a serial membrane system of the sort postulated by Curran and described mathematically by Patlak and associates.

In the physical interpretation of these phenomena it is important to recognize that substitution of impermeant solute on either side has approximately the same effect, but that the effect in the two instances is a result of two distinct attributes of the system. Specifically, the effect of substitution on the left (mucosal) side depends chiefly upon a difference between the reflection coefficients for permeant and impermeant solutes at the primary barrier. The effect of substitution on the right (serosal) side, on the other hand, depends upon a difference in the diffusion permeability of the second (nonselective) barrier for the two solute species. The relative hypertonicity of the absorbate when impermeant solute is present on both sides must then be due to a combination of these two different mechanisms.

Electrical potentials in a serial membrane system. The electrical PD between compartment 1 and compartment $r$ of the model depicted in Figure 9 must depend upon the following factors: 1 ) the electrogenic effect (if any) of active electrolyte transport across the first barrier, 2) the passive diffusion permeabilities of the two barriers for specific ionic species in relation to the steady state concentrations of electrolytes in compartments $1, \mathrm{~m}$, and $\mathrm{r}$, and 3 ) streaming potentials due 
to movement of solution through channels bearing fixed charges in either or both barriers.

Previous experiments in isolated gallbladders of both fish (3) and rabbits (5) suggest that active transport of $\mathrm{NaCl}$ is electrically neutral, whatever the actual mechanism. The passive diffusion permeabilities of individual barriers for specific ionic species are unknown, but the gallbladder as a whole appears to be far more permeant to cations than to anions $(3,5)$. Although the wall of the fish gallbladder as a whole appears to exhibit streaming potentials (3), the question of streaming potentials across individual barriers is unresolved, and it is possible that a serial membrane arrangement might account for "streaming potential" behavior even in the absence of streaming potentials across individual barriers (see below).

In view of this admittedly incomplete experimental background it is of interest to predict the electrical potentials across the theoretical model (Figure 9) under the arbitrary assumptions that $a)$ active transport is electrically neutral, $b$ ) the first barrier is far more permeable for cations than for anions, $c$ ) the second barrier is nonselective with respect to different ionic species, and $d$ ) there are no streaming potentials across individual barriers. These calculations are shown in the Appendix, and the predicted potentials can be compared with observed potentials across the gallbladder wall (Table II) as follows (the sign in each case refers to the left, or mucosal, side) : category $1(\mathrm{~A}, \mathrm{~B}, \mathrm{C})$, permeant solute only: predicted: $0 \mathrm{mv}$, observed: $+1.7 \mathrm{mv}$; category $2 \mathrm{D}$, impermeant solute on both sides (isotonic): predicted: $+8 \mathrm{mv}$, observed: $+8.2 \mathrm{mv}$; category $2 \mathrm{E}$, impermeant solute on both sides (hypertonic) : predicted: $+7 \mathrm{mv}$, observed: $+5.0 \mathrm{mv}$; category $3 \mathrm{~F}$, impermeant solute on right (serosal) side: predicted: $-3 \mathrm{mv}$, observed: $-1.4 \mathrm{mv}$; category $3 \mathrm{G}$, impermeant solute on left (mucosal) side: predicted: $+10 \mathrm{mv}$, observed: $+10.9 \mathrm{mv}$.

In all of the cases considered it is evident, therefore, that the observed electrical behavior of the gallbladder was at least consistent with the predicted behavior of a hypothetical serial membrane system. The excellent quantitative agreement between predicted and observed potentials was of course contingent upon the validity of a number of arbitrary qualifications and numerical constants and can therefore be regarded only as illustrative.

In general, two potentially important properties of a serial membrane arrangement are apparent from this analysis. First, as already emphasized by Kedem and Katchalsky (14) and by Patlak and associates (11), the system may exhibit rectification. Thus, for example, reversing the solutions between compartments 1 and $r$ (as in cases $3 \mathrm{~F}$ and $3 \mathrm{G}$ above) need not result in an equal and opposite electrical potential difference. Second, the system as a whole may exhibit streaming potential behavior even though there are no streaming potentials across the individual barriers. This is attributable to the fact that the solute concentration in the middle compartment is a complex function of both solvent flux and solute flux. If the differential ion permeabilities of the two barriers are not identical, there may arise potential differences across the entire system that cannot be accounted for by concentration differences between the external bathing media (e.g., cases $2 \mathrm{D}$ and $2 \mathrm{E}$ above). Such potential differences may meet the criteria of streaming potentials.

Differences between in vitro and in vivo systems. The isolated gallbladder, in the present experimental design, is called upon to transport solution through the entire thickness of the wall. Structurally the wall, exclusive of the epithelial cell layer, appears to consist of loose connective tissue and smooth muscle with a thin and incomplete peritoneal envelope. Despite the absence of organized structural barriers the wall must encase an essentially unstirred layer of fluid that could function in a manner analogous to the second barrier of Figure 9 and thereby lead to major experimental artifacts in the in vitro system. Coupled water transport, indicated by the capacity to move water against substantial osmotic gradients, is a readily demonstrable phenomenon in the gallbladder whose blood supply is intact. On microscopic examination a rich capillary network is seen to lie immediately adjacent to the epithelial basement membrane, so that normal vascular perfusion must amount, in effect, to direct perfusion of the nutrient surface of the epithelial cell sheet. The in vivo experiments demonstrate, therefore, that whatever structural arrangements are principally responsible for the remarkable coupling between solute and solvent must lie 
within the epithelial cell layer itself and that the coupling phenomenon cannot be regarded as an artifact of the in vitro system.

Nevertheless, the limiting osmotic gradient of approximately 40 to $100 \mathrm{mOsm}$ per $\mathrm{kg}$ against which the gallbladder can transport water in vivo (Figure 2) was no greater than that reported previously (5) for the in vitro preparation despite the fact that solute fluxes, when measured in the in vivo preparation, appeared to be 4 to 5 times as great as those usually observed in vitro (compare $\Delta \mathrm{Na}^{+}$in Tables I and II). Insofar as the serial membrane hypothesis can be applied one would conclude (see Appendix, Equation 17) that the permeability of the second barrier would have to be 4 to 5 times greater in the in vivo system than it is in vitro.

Thus supporting structures of the gallbladder wall are responsible for significant (and unphysiological) quantitative alterations in function when the gallbladder is excised and studied in vitro. These alterations do not vitiate the technique. Moreover, an anatomical locus for the coupling mechanism must be sought within the confines of the epithelial cell layer.

Possible sites of coupling within the epithelial layer. Since the reabsorptive behavior of the gallbladder is so clearly consistent with that predicted for the Curran serial membrane model, an actual structural analog should be sought. Given the appropriate reflection and filtration coefficients, it is theoretically possible for any combination of membranes to act as a coupling mechanism. One anatomical feature of the gallbladder, however, is so striking as to attract particular attention in connection with the present problem. Recent electron microscopic examinations of the gallbladder of the mouse by Hayward (15) and of the dog by Johnson, McMinn, and Birchenough (16) have revealed the presence of dilated intercellular spaces between the loose interdigitations of adjacent epithelial cells. These spaces begin near the junctional complex (where the luminal ends of adjacent cells appear to be firmly cemented together) and are maximally dilated towards the base of the cells. They appear to be bounded at the base by thin lateral cytoplasmic extensions of adjacent cells and by a continuous underlying basement membrane. Preliminary observations in collaboration with Kaye, Lane, Wheeler, and
Whitlock (17) show that these spaces are strikingly dilated in the rabbit gallbladder at times when rapid reabsorption is in progress. It is postulated, therefore, that the intercellular spaces may very well function in a manner analogous to the middle compartment of Figure 9 and that the absorptive process may be driven by active transport of solute across the lateral cell borders into these spaces.

From the structural standpoint the intercellular space of the gallbladder is not precisely analogous to the middle compartment of Figure 9. It is not directly adjacent to the mucosal fluid but rather to an intracellular compartment whose other boundaries face both the mucosal and the serosal media. Thus, instead of the three compartments and two barriers of Figure 9, the correct analog would have to include at least four compartments and four different barriers, and the mathematical analysis would be considerably more complicated. If, on the other hand, the intracellular compartment communicated preferentially with the mucosal rather than the serosal compartment, then its osmolality should be determined mainly by the composition of the mucosal fluid, and the major flux of solute and solvent into the cell should occur across the luminal rather than the basal surface. Under these circumstances the over-all behavior of the gallbladder might well approximate that of a simpler system of the sort depicted in Figure 9. Although the physical characteristics of the individual cell surfaces are unknown, it is at least evident that the total area of the microvillous luminal surface $(15,16)$ is much greater than that of the basal surface so that the supposition of preferential access between the luminal and intracellular compartments does appear reasonable.

Elaborate lateral interdigitations, with potential or actual separation between cells, have also been described by Hayward and Johnston (18) in the epithelium of the colon, a tissue whose functions include transport of large volumes of solution. The present observations, therefore, may have application to a number of tissues other than the gallbladder.

Pinocytosis and other alternative mechanisms. That the absorption of an isotonic solution by the gallbladder may be attributed to pinocytosis has been suggested by Grim (6). In his studies on 
the dog, in which solutions containing various concentrations of sodium chloride were placed in the lumen, and for that matter, in all of the present studies in which sodium chloride alone was employed, the results could conceivably be explained by simple nonselective movement of pinocytotic vacuoles from lumen toward serosa. A comparatively hypertonic solution of sodium chloride, however, was transported when sucrose constituted an appreciable fraction of the total solute concentration in the lumen, and this should rule out pinocytosis as a reasonable possibility. One could only retain the hypothesis by assuming that pinocytotic vacuoles have the capacity selectively to reject sucrose while engulfing a solution of sodium chloride. As noted previously (5) each vacuole would also be required selectively to reject potassium, phenol red, T1824, and methemoglobin in order to account for available data. For all of these reasons, the pinocytosis theory appears inadequate to account for absorption of solution by the gallbladder.

It is theoretically possible that the epithelial cells might form secretory vacuoles that would discharge their contents toward the serosal surface. This is very different from classical pinocytosis and, indeed, would actually represent a variant of the Curran model in which access between the middle and right hand compartment (Figure 9) would be limited by time of exposure rather than by the geometry of the hypothetical second barrier. The possibility of secretory vacuole formation must therefore be retained although there is, at the moment, no actual histologic evidence to support it.

Finally, it is necessary to consider that the coupling between solute and solvent movement might depend upon interactions for which no immediate physical analog can be found, but which have been designated by Diamond (4) as "formally analogous to codiffusion." In Diamond's theoretical treatment of the system the presence of impermeant solute (in equal amounts on both sides) should not have affected the composition of the transported solution, nor for that matter should the composition of the transported solution have been intimately dependent upon the concentration of permeant solute in the media. Thus the results of the present studies are clearly inconsistent with his original formulation. How- ever, in deriving his equations Diamond used the basic assumption that an active transport potential operates across the entire system and that solutesolvent interaction is identical for actively and passively transported solute. It is possible, therefore, that some other arrangement might yield theoretical predictions consistent with the present results and that a codiffusion mechanism of unknown type might provide an explanation for solute-solvent coupling by the gallbladder.

At the present time, however, the Curran serial membrane model appears to yield predictions consistent in every respect with the chemical and electrical events observed under a variety of circumstances in the isolated gallbladder. We feel, therefore, that this model provides the best available working basis for understanding the absorptive phenomena and also the best clue in the search for anatomical localization of the essential components of the system.

\section{Summary}

1) The rabbit gallbladder is capable of absorbing water "uphill" against adverse osmotic gradients as high as $90 \mathrm{mOsm}$ per $\mathrm{kg}$ in vivo as well as in vitro.

2) In the absence of osmotic gradients and in the absence of impermeant solute the osmolality of the solution transported in vitro is approximately equal to the osmolality of the bathing media at 200,284 , and $400 \mathrm{mOsm}$ per $\mathrm{kg}$. Partial isosmotic substitution of impermeant solute (sucrose) on either or both sides of the gallbladder wall decreases the rate of water transport relative to the rate of $\mathrm{Na}^{+}$transport, so that the solution transported is hypertonic with respect to the bathing media.

3) The presence of sucrose on the mucosal side or on both sides is associated with an increase in electrical potential difference (PD) (mucosa positive). The presence of sucrose on the serosal side is associated with a smaller change in PD in the opposite direction.

4) All of the observed characteristics of coupled solute-solvent transport by the gallbladder are explainable by the operation of a serial-membrane system as proposed by Curran. The demonstration of uphill water transport in vivo suggests that the system is contained within the epithelial 
cell layer. The basal intercellular spaces between adjacent columnar cells, which are observable by electron microscopy, may constitute such a system.

\section{Appendix}

a) Effect of changes in bathing media on solvent flux. The following equation of Patlak and associates (11) describes net flux of solvent where the system (Figure 9) is bathed in identical solutions on both sides:

$$
\begin{aligned}
\mathrm{J}_{\mathrm{v}}(\mathrm{D})=\operatorname{LRT}\left(\mathrm{e}^{-\alpha_{2}}-1\right)\left(1-\mathrm{e}^{\alpha_{1}}\right) & \left(\sigma_{1}-\sigma_{2}\right)^{2} \\
& \times\left\{\mathrm{c}-\frac{\mathrm{j}}{\mathrm{J}_{\mathrm{v}}\left(\sigma_{1}-\sigma_{2}\right)}\right\},
\end{aligned}
$$

where $J_{v}=$ steady state flux of solvent, $P_{i}=$ solute permeability of the $\mathrm{i}$ barrier, $\mathrm{L}_{\mathrm{pi}}=$ hydraulic conductivity of the $\mathrm{i}$ barrier, $\sigma_{\mathrm{i}}=$ reflection coefficient of the $\mathrm{i}$ barrier, $\mathfrak{L}=\mathrm{L}_{\mathrm{p} 1} \times \mathrm{L}_{\mathrm{p} 2} /\left[\mathrm{L}_{\mathrm{p} 1}+\mathrm{L}_{\mathrm{p} 2}\right], \quad \alpha_{\mathrm{i}}=\left[\left(1-\sigma_{\mathrm{i}}\right) \mathrm{J}_{\mathrm{v}}\right] / \mathrm{P}_{\mathrm{i}}, \quad \mathrm{j}=$ steady state active transport solute flux (across barrier 1), $\mathrm{D}=\left(1-\sigma_{1}\right)\left(\mathrm{e}^{-\alpha_{2}}-1\right)+\left(1-\sigma_{2}\right)\left(1-\mathrm{e}^{\alpha_{1}}\right)$, and $\mathrm{c}=$ concentration of solute in bathing media.

Rearrangement yields:

$$
\begin{aligned}
& \frac{\mathrm{Jv}_{\mathrm{v}}\left[\left(1-\sigma_{1}\right)\left(1-\mathrm{e}^{-\alpha_{2}}\right)+\left(1-\sigma_{2}\right)\left(\mathrm{e}^{\alpha_{1}}-1\right)\right]}{\left(1-\mathrm{e}^{-\alpha_{2}}\right)\left(\mathrm{e}^{\alpha_{1}}-1\right)} \\
& \quad=\operatorname{LRT}\left(\sigma_{1}-\sigma_{2}\right)^{2}\left\{\frac{\mathrm{j}}{\mathrm{J}_{\mathrm{v}}\left(\sigma_{1}-\sigma_{2}\right)}-\mathrm{c}\right\} .
\end{aligned}
$$

The expression on the left hand side of this equation is a function of $\mathrm{J}_{\mathrm{v}}$ whose first derivative with respect to $\mathrm{J}_{\mathrm{v}}$ is positive for all positive values of $\mathrm{J}_{\mathrm{v}}$ as long as $\sigma_{1}>\sigma_{2}$. Hence this expression must always vary in the same direction as $\mathrm{J}_{\mathrm{v}}$ itself. It follows, from inspection of the equation, that if $j$ remains relatively constant, $J_{v}$ must decrease as $c$ increases and vice versa. Thus there should be an inverse relationship between solvent flux and the tonicity of the bathing media (see Figure 3).

b) Relationship between solute concentration in bathing media and solute "concentration" in transported solution. The following equation of Patlak and associates, which includes the solute "concentration" in transported solution $\left[\mathrm{J}_{\mathrm{s}} / \mathrm{J}_{\mathrm{v}}\right]$, applies in situations where the bathing media are identical:

$$
\mathrm{J}_{\mathrm{v}}=\operatorname{LRT}\left(\sigma_{1}-\sigma_{2}\right)\left(\mathrm{e}^{-\alpha_{2}}-1\right)\left\{\mathrm{c}-\frac{\left[\mathrm{J}_{\mathrm{s}} / \mathrm{J}_{\mathrm{v}}\right]}{\left(1-\sigma_{2}\right)}\right\}
$$

where $\mathrm{J}_{\mathrm{s}}=$ steady state flux of solute.

By rearrangement:

$$
\frac{\mathrm{J}_{\mathrm{v}}}{1-\mathrm{e}^{-\left[\left(1-\sigma_{2}\right) \mathrm{J}_{\mathrm{v}}\right] / \mathrm{P}_{2}}}=\operatorname{LRT}\left(\sigma_{1}-\sigma_{2}\right)\left\{\frac{\left[\mathrm{J}_{\mathrm{s}} / \mathrm{J}_{\mathrm{v}}\right]}{\left(1-\sigma_{2}\right)}-\mathrm{c}\right\} .
$$

The expression on the left hand side of this equation is a function of $J_{v}$ whose first derivative with respect to $J_{v}$ is positive as long as $\mathrm{J}_{\mathrm{v}}$ is positive (which is true whenever $\sigma_{1}>\sigma_{2}$ ). Therefore, this expression must always vary in the same direction as $\mathrm{J}_{\mathrm{v}}$ itself. Moreover, as noted previ- ously, $J_{v}$ (and hence the value of the left hand term) tends to decrease as $c$ increases. Therefore, if $c_{b}>c_{a}$ :

$$
\left\{\frac{\left[\mathrm{J}_{\mathrm{s}} / \mathrm{J}_{\mathrm{v}}\right]_{\mathrm{a}}}{\left(1-\sigma_{2}\right)}-\mathrm{c}_{\mathrm{a}}\right\}>\left\{\frac{\left[\mathrm{J}_{\mathrm{s}} / \mathrm{J}_{\mathrm{v}}\right]_{\mathrm{b}}}{\left(1-\sigma_{2}\right)}-\mathrm{c}_{\mathrm{b}}\right\}
$$

and therefore $\Delta\left[\mathrm{J}_{\mathrm{s}} / \mathrm{J}_{\mathrm{v}}\right]<\Delta \mathrm{c}\left(1-\sigma_{2}\right)$ (for increasing values of c). It is evident, therefore, that $\Delta\left[\mathrm{J}_{\mathrm{s}} / \mathrm{J}_{\mathrm{v}}\right]$ can approach $\Delta \mathrm{c}$ only if $\sigma_{2} \ll 1$.

Assuming $\sigma_{2} \approx 0$, Equation 2 becomes:

$$
\frac{\mathrm{J}_{\mathrm{v}}}{1-\mathrm{e}^{-J_{\mathrm{v}} / \mathrm{P}_{2}}}=\mathfrak{L R T} \sigma_{1}\left\{\left[\mathrm{~J}_{\mathrm{s}} / \mathrm{J}_{\mathrm{v}}\right]-\mathrm{c}\right\}
$$

Let $\left[\mathrm{J}_{\mathrm{s}} / \mathrm{J}_{\mathrm{v}}\right]=(1+\delta) c$. Then $\delta=\left[\mathrm{J}_{\mathrm{v}} /\left(1-\mathrm{e}^{\left.-\mathrm{J}_{\mathrm{v}} / \mathbf{P}_{2}\right)}\right] /\right.$ \&RT $\sigma_{1} \mathrm{c}$, and $\delta \ll 1$ (i.e., $\left[\mathrm{J}_{\mathrm{s}} / \mathrm{J}_{\mathrm{v}}\right] \approx \mathrm{c}$ ), provided that

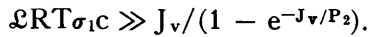

The crucial term in this inequality, $\mathscr{L}$, is an expression of the hydraulic conductivities of the two barriers. Thus if both barriers are readily conductive for solvent and the second barrier is comparatively nonselective $\left(\sigma_{2} \ll 1\right)$, the system may be expected to transport a solution that is nearly isotonic with respect to the bathing media (see Figure 7, A, B, and C).

c) Effect of impermeant solute. Patlak and associates (11) integrated the equations of Kedem and Katchalsky (19) to obtain the following equations, which are applicable to a homogenous barrier of finite thickness:

$$
\mathrm{J}_{\mathrm{v}}=-\mathrm{L}_{\mathrm{p}}[\Delta \mathrm{p}-\sigma \mathrm{RT} \Delta \mathrm{c}]
$$

and

$$
\mathrm{C}_{\mathrm{r}}=\mathrm{c}_{1} \mathrm{e}^{\left[(1-\sigma) J_{\mathrm{v}}\right] / \mathrm{P}}+\frac{\mathrm{J}_{\mathrm{s}}}{(1-\sigma) \mathrm{J}_{\mathrm{v}}}\left(1-\mathrm{e}^{\left[(1-\sigma) \mathrm{J}_{\mathrm{v}}\right] / \mathrm{P}}\right) .
$$

In the presence of two solute species, provided there is no direct interaction between the solutes, Equation 4 would have to be expanded as follows:

$$
\mathrm{J}_{\mathrm{v}}=-\mathrm{L}_{\mathrm{p}}\left[\Delta \mathrm{p}-\sigma \mathrm{RT} \Delta \mathrm{c}_{\mathrm{s}}-\sigma^{\prime} \mathrm{RT} \Delta \mathrm{c}_{\mathrm{i}}\right],
$$

where $\Delta \mathrm{c}_{\mathrm{s}}, \Delta \mathrm{c}_{\mathrm{i}}=$ gradients for the two solutes $\mathrm{s}$ and $\mathrm{i}$, and $\sigma, \sigma^{\prime}=$ reflection coefficients for solutes $\mathrm{s}$ and $\mathrm{i}$, respectively.

Equation 5 would be applicable to either solute provided the appropriate constants were used.

In the present system (Figure 9) application of Equation 6 to the first barrier yields:

$$
\mathrm{J}_{\mathrm{v}}=-\mathrm{L}_{\mathrm{pl}}\left[\Delta \mathrm{p}-\sigma_{1} \mathrm{RT}\left(\mathrm{c}_{\mathrm{ms}}-\mathrm{c}_{\mathrm{ls}}\right)-\sigma_{\mathrm{l}}{ }^{\prime} \mathrm{RT}\left(\mathrm{c}_{\mathrm{mi}}-\mathrm{c}_{\mathrm{li}}\right)\right],
$$

where $\Delta \mathrm{p}=$ hydrostatic pressure gradient from compartment $m$ to compartment 1 .

Assuming there is no net hydrostatic pressure gradient between compartments 1 and $r$, application of Equation 6 to the second barrier yields:

$\mathrm{J}_{\mathrm{v}}=-\mathrm{L}_{\mathrm{p} 2}\left[-\Delta \mathrm{p}-\sigma_{2} \mathrm{RT}\left(\mathrm{c}_{\mathrm{rs}}-\mathrm{c}_{\mathrm{ms}}\right)-\sigma_{2}{ }^{\prime} \mathrm{RT}\left(\mathrm{c}_{\mathrm{ri}}-\mathrm{c}_{\mathrm{mi}}\right)\right]$.

Equations 7 and 8 may be combined, eliminating $\Delta \mathrm{p}$ :

$$
\begin{aligned}
\mathrm{J}_{\mathrm{v}}=\operatorname{LRT}\left[\left(\sigma_{1}-\sigma_{2}\right) \mathrm{c}_{\mathrm{ms}}+\right. & \left(\sigma_{1}{ }^{\prime}-\sigma_{2}{ }^{\prime}\right) \mathrm{c}_{\mathrm{mi}}+\sigma_{2} \mathrm{C}_{\mathrm{rs}} \\
+ & \left.+\sigma_{2}{ }^{\prime} \mathrm{C}_{\mathrm{ri}}-\sigma_{1} \mathrm{C}_{\mathrm{ls}}-\sigma_{1}{ }^{\prime} \mathrm{c}_{\mathrm{li}}\right]
\end{aligned}
$$


From Equation 5, applied to the second barrier, one obtains the following:

$\mathrm{C}_{\mathrm{mg}}=\mathrm{C}_{\mathrm{rs}} \mathrm{e}^{-\left[\left(1-\sigma_{2}\right) \mathrm{J}_{\mathrm{v}}\right] / \mathrm{P}_{2}}+\frac{\mathrm{J}_{\mathrm{s}}}{\left(1-\sigma_{2}\right) \mathrm{J}_{\mathrm{v}}}\left(1-\mathrm{e}^{\left.-\left[\left(1-\sigma_{2}\right) J_{\mathrm{v}}\right] / \mathbf{P}_{2}\right)}\right.$,

and

$$
\begin{aligned}
& \mathrm{c}_{\mathrm{mi}}=\mathrm{c}_{\mathrm{ri}} \mathrm{e}^{-\left[\left(1-\sigma_{2^{\prime}}\right) J_{\mathrm{v}}\right] / \mathbf{P}_{2^{\prime}}} \\
& \quad+\frac{\mathrm{J}_{\mathrm{i}}}{\left(1-\sigma_{2}^{\prime}\right) J_{\mathrm{v}}}\left(1-\mathrm{e}^{\left.-\left[\left(1-\sigma_{2^{\prime}}\right) J_{\mathrm{v}}\right] / \mathbf{P}_{2^{\prime}}\right),}\right.
\end{aligned}
$$

where $\mathrm{J}_{\mathrm{s}}, \mathrm{J}_{\mathrm{i}}=$ net solute fluxes for solutes $\mathrm{s}$ and $\mathrm{i}$, and $\mathrm{P}_{2}, \mathrm{P}_{2}{ }^{\prime}=$ solute permeability of the second barrier for $\mathrm{s}$ and $i$, respectively. Substitution of Equations 10 and 11 into 9 yields the general expression:

$$
\begin{array}{r}
\mathrm{J}_{\mathrm{v}}=\mathcal{L} \mathrm{RT}\left[\left(\sigma_{1}-\sigma_{2}\right) \mathrm{C}_{\mathrm{rs}} \mathrm{e}^{-\left[\left(1-\sigma_{2}\right) \mathrm{J}_{\mathrm{v}}\right] / \mathrm{P}_{2}}+\frac{\left(\sigma_{1}-\sigma_{2}\right) \mathrm{J}_{\mathrm{s}}}{\left(1-\sigma_{2}\right) \mathrm{J}_{\mathrm{v}}}\right. \\
\times\left(1-\mathrm{e}^{\left.-\left[\left(1-\sigma_{2}\right) \mathrm{J}_{\mathrm{v}}\right] / \mathrm{P}_{2}\right)}+\left(\sigma_{1}{ }^{\prime}-\sigma_{2}{ }^{\prime}\right) \mathrm{C}_{\mathrm{ri}} \mathrm{e}^{-\left[\left(1-\sigma_{2}{ }^{\prime}\right) \mathrm{J}_{\mathrm{v}}\right] / \mathrm{P}_{2}{ }^{\prime}}\right. \\
+\frac{\left(\sigma_{1}{ }^{\prime}-\sigma_{2}{ }^{\prime}\right) \mathrm{J}_{\mathrm{i}}}{\left.\left(1-\sigma_{2}\right)\right) \mathrm{J}_{\mathrm{v}}}\left(1-\mathrm{e}^{\left.-\left[\left(1-\sigma_{2}{ }^{\prime}\right) \mathrm{J}_{\mathrm{v}}\right] / \mathrm{P}_{2}{ }^{\prime}\right)+\sigma_{2} \mathrm{C}_{\mathrm{rs}}}\right. \\
\left.+\sigma_{2}{ }^{\prime} \mathrm{C}_{\mathrm{ri}}-\sigma_{1} \mathrm{C}_{\mathrm{ls}}-\sigma_{1}{ }^{\prime} \mathrm{C}_{\mathrm{li}}\right]
\end{array}
$$

In the case where the first barrier is assumed to be impermeable to solute $\mathrm{i}$, then $\mathrm{J}_{\mathrm{i}}=0$, and $\sigma_{1}{ }^{\prime} \approx 1$. If the second barrier is assumed to be nonselective for both solutes, then $\sigma_{2}=\sigma_{2}{ }^{\prime}=0$. Under these circumstances Equation 12 reduces to the following:

$$
\begin{array}{r}
J_{v}=\mathscr{L R T}\left[\sigma_{1}\left(c_{r s} e^{-J_{v} / P_{2}}+\frac{J_{s}}{J_{v}}\left[1-\mathrm{e}^{-J_{v} / P_{2}}\right]-c_{l s}\right)\right. \\
\left.+\left(c_{r i} \mathrm{e}^{-J_{v} / P_{2_{2}^{\prime}}}-c_{l i}\right)\right] .
\end{array}
$$

Three special cases are considered:

a) Impermeant solute on both sides $\left(\mathrm{c}_{\mathrm{ls}}=\mathrm{c}_{\mathrm{rs}}=\mathrm{c}_{\mathrm{s}}, \mathrm{c}_{\mathrm{li}}=\right.$ $\left.\mathrm{c}_{\mathrm{ri}}=\mathrm{c}_{\mathrm{i}}\right)$. Then, from Equation 13:

$$
\begin{aligned}
\frac{\mathrm{J}_{\mathrm{v}}}{1-\mathrm{e}^{-\mathrm{J}_{\mathrm{v}} / \mathbf{P}_{2}}}= & \operatorname{LRT}_{\sigma_{1}}\left\{\frac{\mathrm{J}_{s}}{\mathrm{~J}_{\mathrm{v}}}\right. \\
& \left.-\left[\mathrm{c}_{\mathrm{s}}+\mathrm{c}_{\mathrm{i}}\left(\frac{\left[1-\mathrm{e}^{\left.-\mathrm{J}_{\mathrm{v}} / \mathrm{P}_{2^{\prime}}\right]}\right.}{\sigma_{1}\left[1-\mathrm{e}^{\left.-\mathrm{J}_{\mathrm{v}} / \mathbf{P}_{2}\right]}\right.}\right)\right]\right\} .
\end{aligned}
$$

b) Impermeant solute on right side $\left(\mathrm{c}_{1 \mathrm{i}}=0, \mathrm{c}_{\mathrm{rs}}+\mathrm{c}_{\mathrm{r} \mathrm{i}}\right.$ $=\mathrm{c}_{\mathrm{ls}}$ ). Then, from Equation 13:

$$
\begin{aligned}
\frac{\mathrm{J}_{\mathrm{v}}}{1-\mathrm{e}^{-\mathrm{J}_{\mathrm{v}} / \mathrm{P}_{2}}} & =\operatorname{LRT} \sigma_{1}\left\{\frac{\mathrm{J}_{\mathrm{s}}}{\mathrm{J}_{\mathrm{v}}}\right. \\
- & {\left.\left[\mathrm{c}_{\mathrm{rs}}+\mathrm{c}_{\mathrm{ri}}\left(\frac{\sigma_{1}-1+\left[1-\mathrm{e}^{-\mathrm{J}_{\mathrm{v}} / \mathbf{P}_{2^{\prime}}}\right]}{\sigma_{1}\left[1-\mathrm{e}^{-\mathrm{J}_{\mathrm{v}} / \mathbf{P}_{2}}\right]}\right)\right]\right\} . }
\end{aligned}
$$

c) Impermeant solute on left side $\left(\mathrm{c}_{\mathrm{ri}}=0, \mathrm{c}_{\mathrm{ls}}+\mathrm{c}_{\mathrm{li}}=\mathrm{c}_{\mathrm{rs}}\right)$. Then, from equation 13 :

$$
\begin{aligned}
\frac{\mathrm{J}_{\mathrm{v}}}{1-\mathrm{e}^{-\mathrm{J}_{\mathrm{v}} / \mathrm{P}_{2}}} & =\operatorname{LRT}_{\sigma_{1}}\left\{\frac{\mathrm{J}_{s}}{\mathrm{~J}_{\mathrm{v}}}\right. \\
- & {\left.\left[\mathrm{c}_{\mathrm{ls}}+\mathrm{c}_{\mathrm{li}}\left(1+\frac{\left(1-\sigma_{1}\right)}{\sigma_{1}\left[1-\mathrm{e}^{-\mathrm{J}_{\mathrm{v}} / \mathrm{P}_{2}}\right]}\right)\right]\right\} . }
\end{aligned}
$$

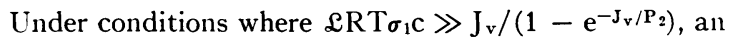
approximate value for $\left(\mathrm{J}_{\mathrm{s}} / \mathrm{J}_{\mathrm{v}}\right)$ can be obtained from each of these equations by assuming that the expression within the braces is equal to zero (see preceeding section). To carry out numerical substitutions a reasonable value for $\mathrm{P}_{2}$ can be obtained by using the results of previous experiments (5) in which it was found that solvent flux across the gallbladder wall in vitro was reduced to zero by addition of approximately 80 mmoles of impermeant solute to the mucosal side. Under conditions where $c_{r s}=c_{l s}$ and $c_{r i}=0$, Equation 13 reduces to the following expression as $\mathrm{J}_{\mathrm{v}}$ approaches zero:

$$
0=\mathscr{L R T}\left[\sigma_{1}\left(\mathrm{~J}_{\mathrm{s}} / \mathrm{P}_{2}\right)-\mathrm{c}^{*}{ }_{1 \mathrm{i}}\right],
$$

from which:

$$
\mathrm{P}_{2}=\sigma_{1} \mathrm{~J}_{\mathrm{s}} / \mathrm{c}^{*}{ }_{1 \mathrm{i}}
$$

where $c^{*}{ }_{1 \mathrm{i}}$ is the concentration of impermeant solute just sufficient to arrest net water movement.

If, as in an average gallbladder, $\mathrm{c}^{*}{ }_{1 \mathrm{i}} \approx 0.08 \mu$ mole per $\mu 1$ and $\mathrm{J}_{\mathrm{s}} \approx 60 \mu$ moles per hour (corresponding to a $\Delta \mathrm{Na}^{+}$of $30 \mu \mathrm{Eq}$ per hour, see Table II), and if it is assumed arbitrarily that $\sigma_{1}=0.9$, then from Equation $17 \mathrm{P}_{2} \approx 675 \mu 1$ per hour. If it is assumed that $\mathrm{J}_{\mathrm{v}} \approx 200 \mu 1$ per hour in the absence of osmotic gradients (see $\Delta \mathrm{w}$ in Table II), then $\left(1-\mathrm{e}^{\left.-\mathrm{J}_{\mathbf{v}} / \mathrm{P}_{2}\right)} \approx 0.26\right.$. If $\mathrm{P}_{2}{ }^{\prime}=\frac{1}{3} \mathrm{P}_{2}{ }^{8}$ then $\left(1-\mathrm{e}^{-\mathrm{J}_{\mathrm{v}} / \mathrm{P}_{2}{ }^{\prime}}\right)$ $\approx 0.59$.

Substitution of the foregoing numerical values into Equations 14, 15, and 16, under conditions where the transported solution is approximately isotonic in the absence of impermeant solute [i.e., where $2 R T \sigma_{1} C \gg J_{v} /\left(1-e^{\left.-J_{v} / P_{2}\right)}\right]$ yieids the predictions listed in the Discussion. The transported solution is hypertonic whenever impermeant solute is present on either or both sides of the system.

d) Electrical potential gradients. The concentration of permeant solute in compartment $\mathrm{m}$ (Figure 9) may be estimated from Equation 10 , for the case in which $\sigma_{2} \approx 0$ :

$$
c_{m s}=c_{r s} e^{-J_{v} / P_{2}}+\frac{J_{s}}{J_{v}}\left(1-e^{-J_{v} / P_{2}}\right) .
$$

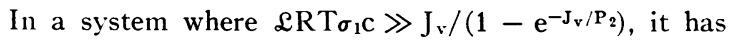
been shown that $\left[\mathrm{J}_{\mathrm{s}} / \mathrm{J}_{\mathrm{v}}\right] \approx \mathrm{c}_{\mathrm{s}}$, and therefore, from Equation $18, \mathrm{c}_{\mathrm{ms}} \approx \mathrm{c}_{\mathrm{s}}$ in the absence of impermeant solute. In the presence of impermeant solute, estimates for $\left[\mathrm{J}_{\mathrm{s}} / \mathrm{J}_{\mathrm{v}}\right]$ based on Equations 14, 15, and 16 may be substituted into Equation 18 to yield the following:

a) Impermeant solute on both sides.

$$
\mathrm{c}_{\mathrm{ms}} \approx \mathrm{c}_{\mathrm{s}}+\frac{\mathrm{c}_{\mathrm{i}}}{\sigma_{1}}\left(1-\mathrm{e}^{-\mathrm{J}_{\mathbf{v}} / \mathbf{P}_{\mathbf{2}^{\prime}}}\right) .
$$

b) Impermeant solute on right side.

$$
\mathrm{c}_{\mathrm{ms}} \approx \mathrm{c}_{\mathrm{rs}}+\mathrm{c}_{\mathrm{ri}}\left(\frac{\sigma_{1}-1+\left[1-\mathrm{e}^{-\mathrm{J}_{\mathrm{v}} / \mathrm{P}_{2^{\prime}}}\right]}{\sigma_{1}}\right) .
$$

${ }^{8}$ Based on coefficients of free diffusion in aqueous solutions of $0.5 \times 10^{-5} \mathrm{~cm}^{2} \mathrm{sec}^{-1}$ for sucrose and $1.5 \times 10^{-5} \mathrm{~cm}^{2}$ $\sec ^{-1}$ for $\mathrm{NaCl}(20)$. 
c) Impermeant solute on left side.

$$
\mathrm{c}_{\mathrm{ms}} \approx \mathrm{c}_{\mathrm{rs}}+\mathrm{c}_{\mathrm{li}}\left(\frac{1-\sigma_{1}}{\sigma_{1}}\right)
$$

By knowing the value for $\mathrm{c}_{\mathrm{ms}}$, and assuming that the first barrier is far more permeable for cations than for anions, the passive diffusion potential across this barrier can be predicted from the Nernst equation: $(\mathrm{PD})_{1} \approx(\mathrm{RT} / \mathrm{F})$ $\ln \left(c_{m s} / c_{1 s}\right)$. The very small junction potential across the second barrier, which is assumed to be nonselective with respect to different ionic species, can be estimated from a rough empirical formula: $(P D)_{2} \approx k\left(c_{m s}-c_{r s}\right)$, where $\mathrm{k} \approx .015 \mathrm{mv}$ per mOsm (based on measurements using bridges filled with different sodium chloride solutions within the concentration range encountered in these studies). Then the PD from 1 to $r=(P D)_{1}+(P D)_{2}$

If it is assumed, as in the preceding section, that $\sigma_{1}=0.9$ and $\left(1-\mathrm{e}^{-\mathrm{J}_{\mathbf{v}} / \mathbf{P}_{2}{ }^{\prime}}\right)=0.59$, then these values, together with the appropriate concentrations of permeant and impermeant solute in the media (Table II) may be substituted into Equations 19, 20, and 21 to obtain estimates for $c_{m s}$ in each case. Based on the assumptions in the preceding paragraph, the values of $c_{m s}$ so obtained have been used to predict the electrical potentials shown in the Discussion.

\section{Addendum}

Since submission of this manuscript two papers dealing with the behavior of rabbit gallbladder have been published by Diamond $(21,22)$. The local osmosis mechanism proposed by Diamond to explain solvent transport is a special case of the serial membrane system, and his equations can be derived directly from those of Patlak and associates (11) subject to the restrictions that the second barrier is entirely nonselective and has negligible solute diffusion permeability and the first barrier is perfectly semipermeable (i.e., $\left.\sigma_{2}=0, P_{2}=0, \sigma_{1}=1\right)$. As noted in our Discussion only the first restriction $\left(\sigma_{2} \approx 0\right)$ is necessary, and the others need be less severe (i.e., $\mathrm{P}_{2}<\%, \sigma_{1}>0$ ).

The existence of separate parallel pathways for active and passive solvent transport (22) seems quite possible on anatomical grounds (15-17). However, the over-all passive resistance of a serial membrane system to osmotic flow is necessarily greater than the sum of the resistances of its component membranes (14), and such a system may also develop apparent "streaming potentials" when impermeant nonelectrolytes are added to the bathing media (see Discussion). Thus neither the high resistance to passive osmotic flow (22) nor the apparent streaming potentials $(22,23)$ observed in the rabbit gallbladder can necessarily be attributed to the operation of independent parallel pathways for active and passive solvent movement.

The present data on "absorbate" composition agree completely with Diamond's for the case where the lumen contains only permeant solute. The apparent discrepancy in observations obtained with sucrose in the lumen can be attributed to differences in experimental design. In Diamond's "unilateral" preparation, in which the gallbladder generates its own serosal bathing medium (i.e., $c_{r s}=J_{s} / J_{V}$ and $c_{r i}=0$ ), Equation 13 reduces to the following :

$$
\mathrm{J}_{\mathrm{v}}=\mathscr{L} \mathrm{RT}^{\prime} \sigma_{1}\left\{\mathrm{~J}_{\mathrm{s}} / \mathrm{J}_{\mathrm{v}}-\mathrm{c}_{\mathrm{ls}}-\mathrm{c}_{\mathrm{li}} / \sigma_{\mathrm{l}}\right\} .
$$

Hence, in the case where $\mathscr{L} \mathrm{RT}_{1} \mathrm{c} \gg \mathrm{Jv}_{\mathrm{v}} /\left(1-\mathrm{e}^{-\mathrm{J}_{\mathrm{v}} / \mathrm{P}_{2}}\right)$, and where it is assumed arbitrarily that $\sigma_{1}=0.9$, one would predict $\mathrm{J}_{\mathrm{s}} / \mathrm{J}_{\mathrm{v}} \approx \mathrm{c}_{\mathrm{ls}}+1.1 \mathrm{c}_{\mathrm{li}}$ in a serial membrane system operated as a "unilateral" preparation in contrast to a prediction of $\mathrm{J}_{\mathrm{s}} / \mathrm{J}_{\mathrm{v}} \approx \mathrm{c}_{\mathrm{ls}}+1.4 \mathrm{c}_{\mathrm{li}}$ in the present experimental design (from Equation 16). If, for example, $30 \%$ of the total luminal osmotic contents consisted of sucrose, the transported solution should be hypertonic by only $3 \%$ in the "unilateral" preparation (and thus appear to be isotonic), whereas it should be hypertonic by $12 \%$ in our preparation. Thus the different results obtained by these two techniques may, when taken together, provide additional support for the serial membrane hypothesis.

\section{Acknowledgments}

We thank Mrs. Elizabeth Ross for her invaluable assistance with the experiments and analytical work. We are grateful to Dr. Pier Mancusi-Ungaro for his helpful suggestions and to Dr. David Schachter for suggesting the fluorescein technique.

\section{References}

1. Whitlock, R. T., P. L. Mancusi-Ungaro, and H. O. Wheeler. Effect of osmolality on water absorption by the gallbladder. Fed. Proc. 1963, 22, 622.

2. Diamond, J. M. The reabsorptive function of the gall-bladder. J. Physiol. (Lond.) 1962, 161, 442.

3. Diamond, J. M. The mechanism of solute transport by the gall-bladder. J. Physiol. (Lond.) 1962, 161, 474.

4. Diamond, J. M. The mechanism of water transport by the gall-bladder. J. Physiol. (Lond.) 1962, $161,503$.

5. Wheeler, H. O. Transport of electrolytes and water across wall of rabbit gall bladder. Amer. J. Physiol. 1963, 205, 427.

6. Grim, E. A mechanism for absorption of sodium chloride solutions from the canine gall bladder. Amer. J. Physiol. 1963, 205, 247.

7. Parsons, D. S., and D. L. Wingate. The effect of osmotic gradients on fluid transfer across rat intestine in vitro. Biochim. biophys. Acta (Amst.) 1961, 46, 170.

8. Curran, P. F. Na, $\mathrm{Cl}$ and water transport by rat ileum in vitro. J. gen. Physiol. 1960, 43, 1137.

9. Curran, P. F., and J. R. McIntosh. A model system for biological water transport. Nature (Lond.) 1962, 193, 347.

10. Ogilvie, J. T., J. R. McIntosh, and P. F. Curran. Volume flow in a series-membrane system. Biochim. biophys. Acta (Amst.) 1963, 66, 441.

11. Patlak, C. S., D. A. Goldstein, and J. F. Hoffman. The flow of solute and solvent across a two-membrane system. J. theor. Biol. 1963, 5, 426. 
12. Krebs, H. A., and K. Henseleit. Untersuchungen uber die Harnstoffbildung im Tierkorper. HoppeSeylers Z. physiol. Chem. 1932, 210, 33.

13. Schreiner, G. E. Determinations of inulin by means of resorcinol. Proc. Soc. exp. Biol. (N. Y.) 1950, 74, 117.

14. Kedem, O., and A. Katchalsky. Permeability of composite membranes, Part 3.-Series array of elements. Trans. Faraday Soc. 1963, 59, 1941.

15. Hayward, A. F. Aspects of the fine structure of the gall bladder epithelium of the mouse. J. Anat. (Lond.) 1962, 96, 227.

16. Johnson, F. R., R. M. H. McMinn, and R. F. Birchenough. The ultrastructure of the gall-bladder epithelium of the dog. J. Anat. (Lond.) 1962, 96, 477.

17. Kaye, G. I., N. Lane, H. O. Wheeler, and R. T. Whitlock. Electron microscopic evidence for a large intercellular fluid space in rabbit gall bladder epithelium functioning in vitro in Proceedings of the 3rd European Regional Conference on Electron Microscopy, Prague, 1964. In press.

18. Hayward, A. F., and H. S. Johnston. The fine structure of the epithelium of the colon in the mouse. Scot. med. J. 1961, 6, 416.

19. Kedem, O., and A. Katchalsky. Thermodynamic analysis of the permeability of biological membranes to non-electrolytes. Biochim. biophys. Acta (Amst.) 1958, 27, 229.

20. Handbook of Chemistry and Physics, 43rd ed. Cleveland, Chemical Rubber Publishing Co., 1961, pp. 2228, 2229.

21. Diamond, J. M. Transport of salt and water in rabbit and guinea pig gall bladder. J. gen. Physiol. 1964, 48, 1.

22. Diamond, J. M. The mechanism of isotonic water transport. J. gen. Physiol. 1964, 48, 15.

23. Pidot, A. L., and J. M. Diamond. Streaming potentials in a biological membrane. Nature (Lond.) 1964, 201, 701.

\section{NOTICE TO AUTHORS}

Beginning with papers accepted January 1, 1965, THE JOURNAL OF CLINICAL INVESTIGATION will charge $\$ 10.00$ per page for each article published, provided that the author's research funds or the institution that supported the research can bear this cost. 